\title{
Biomolecular Interactions and Responses
} of Human Epithelial and Macrophage Cells to Engineered Nanomaterials

George D. Bachand, Amy Allen, Marlene Bachand, Jesse S. Aaron, Jerilyn A. Timlin, Komandoor E. Achyuthan, Adrienne C. Greene, Paul G. Kotula, Jean-Clare Seagrave, and Susan M. Brozik

Prepared by

Sandia National Laboratories

Albuquerque, New Mexico 87185 and Livermore, California 94550

Sandia National Laboratories is a multi-program laboratory managed and operated by Sandia Corporation,

a wholly owned subsidiary of Lockheed Martin Corporation, for the U.S. Department of Energy's

National Nuclear Security Administration under contract DE-AC04-94AL85000.

Approved for public release; further dissemination unlimited. 
Issued by Sandia National Laboratories, operated for the United States Department of Energy by Sandia Corporation.

NOTICE: This report was prepared as an account of work sponsored by an agency of the United States Government.

Neither the United States Government, nor any agency thereof, nor any of their employees, nor any of their contractors, subcontractors, or their employees, make any warranty, express or implied, or assume any legal liability or responsibility for the accuracy, completeness, or usefulness of any information, apparatus, product, or process disclosed, or represent that its use would not infringe privately owned rights. Reference herein to any specific commercial product, process, or service by trade name, trademark, manufacturer, or otherwise, does not necessarily constitute or imply its endorsement, recommendation, or favoring by the United States Government, any agency thereof, or any of their contractors or subcontractors. The views and opinions expressed herein do not necessarily state or reflect those of the United States Government, any agency thereof, or any of their contractors.

Printed in the United States of America. This report has been reproduced directly from the best available copy.

Available to DOE and DOE contractors from

U.S. Department of Energy

Office of Scientific and Technical Information

P.O. Box 62

Oak Ridge, TN 37831

Telephone: $\quad$ (865)576-8401

Facsimile: (865)576-5728

E-Mail: $\quad$ reports@adonis.osti.gov

Online ordering: http://www.osti.gov/bridge

Available to the public from

U.S. Department of Commerce

National Technical Information Service

5285 Port Royal Rd

Springfield, VA 22161

Telephone: $\quad$ (800)553-6847

Facsimile: (703)605-6900

E-Mail: $\quad$ orders@ntis.fedworld.gov

Online order: http://www.ntis.gov/help/ordermethods.asp?loc=7-4-0\#online

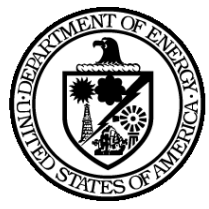


SAND2011-9250

Unlimited Release

Printed December 2011

\title{
Biomolecular Interactions and Responses of Human Epithelial and Macrophage Cells to Engineered Nanomaterials
}

\author{
George Bachand, Amy Allen, Marlene Bachand, Jesse Aaron, Jeri Timlin, Komandoor \\ Achyuthan, Adrienne Greene, Paul Kotula, Jean-Clare Seagrave, and Susan Brozik
}

Sandia National Laboratories

Albuquerque, NM 87185

\begin{abstract}
Engineered nanomaterials (ENMs) are increasingly being used in commercial products, particularly in the biomedical, cosmetic, and clothing industries. For example, pants and shirts are routinely manufactured with silver nanoparticles to render them "wrinkle-free." Despite the growing applications, the associated environmental health and safety (EHS) impacts are completely unknown. The significance of this problem became pervasive within the general public when Prince Charles authored an article in 2004 warning of the potential social, ethical, health, and environmental issues connected to nanotechnology. The EHS concerns, however, continued to receive relatively little consideration from federal agencies as compared with large investments in basic nanoscience R\&D. The mounting literature regarding the toxicology of ENMs (e.g., the ability of inhaled nanoparticles to cross the blood-brain barrier; Kwon et al., 2008, J. Occup. Health 50, 1) has spurred a recent realization within the NNI and other federal agencies that the EHS impacts related to nanotechnology must be addressed now. In our study we proposed to address critical aspects of this problem by developing primary correlations between nanoparticle properties and their effects on cell health and toxicity. A critical challenge embodied within this problem arises
\end{abstract}


from the ability to synthesize nanoparticles with a wide array of physical properties (e.g., size, shape, composition, surface chemistry, etc.), which in turn creates an immense, multidimensional problem in assessing toxicological effects. In this work we first investigated varying sizes of quantum dots (Qdots) and their ability to cross cell membranes based on their aspect ratio utilizing hyperspectral confocal fluorescence microscopy. We then studied toxicity of epithelial cell lines that were exposed to different sized gold and silver nanoparticles using advanced imaging techniques, biochemical analyses, and optical and mass spectrometry methods. Finally we evaluated a new assay to measure transglutaminase (TG) activity; a potential marker for cell toxicity. 


\section{CONTENTS}

ABSTRACT ............................................................................................................................. 3

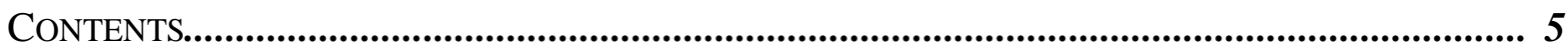

1. Advanced Optical Imaging Reveals Dependence of Particle Geometry on Interactions between CdSe Quantum Dots and Immune Cells..............................................7

1.1 Chapter Summary

1.2 Introduction

1.3 Results and Discussion

1.3.1 Particle Characterization

1.3.2 Particle Diffusion in the Cellular Membrane

1.3.3 Particle Uptake Kinetics

1.3.4 Particle Partitioning in the Cell Membrane

1.3.5 Nanoparticle Sorting to Lysosomes

1.4 Conclusions

1.5 Experimental Section

1.6 References

2. Induced IL-8 Response in Human Alveolar Basal Epithelial Cells Following Exposure to Gold and Silver Nanoparticles ..........................................................25

2.1 Chapter Summary

2.2 Introduction

2.3 Materials and Methods

2.4 Results and Discussion

2.4.1 Temporal response to AuNPs and AgNPs

2.4.2 Dose-dependent response in WST-1 and IL-8

2.5 Conclusions

2.6 References

3. High-throughput Screening of Transglutaminase Activity using Plasmonic Fluorescent Nanocomposites .... 39

3.1 Chapter Summary

3.2 Introduction

3.3 Materials and Methods 


\subsubsection{Materials}

3.3.2 High-Throughput Screening (HTS) of TG Catalysis

3.3.3 Plasmonic Fluorescent Nanocomposites

3.4 Results and Discussion

3.4.1 Assay format

3.4.2 Theory of plasmonic fluorescent nanocomposites

3.4.3 Clear versus white plates

3.4.4 Optimization of $T G$ reactants

3.4.5 Optimization of plasmonic fluorescent nanocomposites

3.4.6 Reaction kinetics

3.4.7 Assay simplification

3.4.8 Absorption assay

3.5 Conclusions

3.6 References 


\section{Advanced Optical Imaging Reveals Dependence of Particle Geometry on Interactions between CdSe Quantum Dots and Immune Cells}

\subsection{Chapter Summary}

The biocompatibility and possible toxicological consequences of engineered nanomaterials, including quantum dots (QDs) due to their unique suitability for biomedical applications, remain intense areas of interest. We utilized advanced imaging approaches to characterize the interactions of CdSe QDs of various sizes and shapes with live immune cells. Particle diffusion and partitioning within the plasma membrane, cellular uptake kinetics, and sorting of particles into lysosomes were all independently characterized. Using high-speed total internal reflectance fluorescence (TIRF) microscopy, we show that QDs with an average aspect ratio of 2.0 (i.e., rod-shaped) diffuse nearly an order of magnitude slower in the plasma membrane than more spherical particles with aspect ratios of 1.2 and 1.6, respectively. Moreover, more rod-shaped QDs were shown to be internalized into the cell 23 fold more slowly. Hyperspectral confocal fluorescence microscopy demonstrates that QDs tend to partition within the cell membrane into regions containing a single particle type. Furthermore, data examining QD sorting mechanisms indicate that endocytosis and lysosomal sorting increases with particle size. Together, these observations suggest that both size and aspect ratio of a nanoparticle are important characteristics that significantly impact interactions with the plasma membrane, uptake into the cell, and localization within intracellular vesicles. Thus, rather than simply characterizing nanoparticle uptake into cells, we show that utilization of advanced imaging approaches permits a more nuanced and complete examination of the multiple aspects of cell-nanoparticle interactions that can ultimately aid understanding possible mechanisms of toxicity, resulting in safer nanomaterial designs.

\subsection{Introduction}

The incorporation of engineered nanomaterials into a wide variety of applications has created vast new technological and commercial opportunities. Indeed, over 1000 products in the U.S. market alone have thus far been identified to contain particles with one or more

dimension within the $1-100 \mathrm{~nm}$ size regime. ${ }^{[1]}$ In addition, numerous nanomaterials are being 
investigated, or are already implemented, for biomedical applications such as targeted therapeutics ${ }^{[2-5]}$ and imaging agents. ${ }^{[6-10]}$ Despite such uses, a thorough understanding of the physiological risks and possible toxicological consequences of these materials has lagged behind their implementation. For example, while carbon nanotubes have been synthesized since at least the early 1990s, ${ }^{[11]}$ animal pilot studies suggesting their potential toxicological and carcinogenic effects did not appear until over a decade later. ${ }^{[12-13]}$ To date, the majority of reports investigating the toxicology of nanomaterials have concentrated on acquiring doseresponse data in cells and small animals after challenge with nanoparticles of various materials. ${ }^{[14-18]}$ Further, there have been a number of studies focused on the influence of nanoparticle surface chemical properties on uptake with respect to possible mechanistic underpinnings for toxicity. ${ }^{[19-25]}$ For example, the surface coating of QDs did not affect uptake by human epidermal keratinocytes, but did significantly impact the release of cytokines. ${ }^{[20]}$ This observation contrasts recent findings that suggest carboxylic acid-coated QDs are internalized in epithelial cell lines, whereas amine- or polythene glycol- coated QDs are not taken up. ${ }^{[26]}$ In addition, Chan and colleagues have demonstrated a size and shape dependency for gold nanoparticle uptake and endocytosis, ${ }^{[27-28]}$ which may provide further insight into the relationship between ceullar uptake and potential cytotoxicity. The goal of our work was to apply advanced optical imaging techniques to assess whether particle shape and size dependencies exist for carboxyl-terminated CdSe QD uptake into non-phagocytotic mast cells, and to develop a better understanding of how the physical properties of nanoparticles modulate uptake, which ultimately can inform future toxicological studies.

QDs are among the most widely utilized nanomaterials in research settings, particularly for biomedical investigations, due to their utility as optical tracers and probes, both in vitro and in vivo. ${ }^{[29-34]}$ In an effort to attain a better mechanistic understanding of their interactions with immune cells (a likely scenario in the case of systemic exposure during small animal imaging studies), ${ }^{[35]}$ we investigated the behavior of variously sized/shaped QDs after exposure to rat basophilic leukemia (RBL) cells, a well-characterized immune cell model. ${ }^{[36]}$ We incorporated both high-speed TIRF microscopy ${ }^{[37]}$ and hyperspectral confocal fluorescence $(\mathrm{HCF})$ microscopy ${ }^{[38-39]}$ to gauge various biological behaviors of three different QD types, characterized by peak fluorescence emission wavelengths of 585, 605, and $655 \mathrm{~nm}$. 
The behaviors we probed include (1) particle diffusion and (2) partitioning within the plasma membrane, (3) uptake and/or endocytosis kinetics, as well as (4) sorting of QDs into lysosomal vesicles, all within live RBL cells. We observed that while overall QD size does not predictably affect their dynamic behaviors on the cell membrane, there is a clear dependence on particle aspect ratio. Interestingly, however, the ultimate fate within the endocytotic sorting mechanisms of the cell is primarily particle size dependent. Overall, our unique use of TIRF and HCF microscopy allows examination of the discrete behaviors of nanoparticles throughout their multi-step processing within live cells.

\subsection{Results and Discussion}

\subsubsection{Particle Characterization}

Three varieties of CdSe QDs, characterized by the manufacturer via their peak fluorescence emission wavelengths of $585 \mathrm{~nm}, 605 \mathrm{~nm}$, and $655 \mathrm{~nm}$, were obtained commercially (Invitrogen). In order to independently assess the size and shape properties for each of these particle types, QD samples were imaged using a scanning transmission electron microscope (STEM) (Tecnai F-30ST, FEI Company). STEM imaging offers advantages over conventional TEM due to the incorporation of a high-angle annular dark-field (HAADF) detector, which is sensitive to electrons that are scattered by the sample, not transmitted electrons as in conventional TEM. This technique results in positive contrast from the sample, which ideally varies as the square of the atomic number $\left(Z^{2}\right)$ of the samples' constituent elements, ${ }^{[40]}$ and allows higher detection sensitivity. The resulting STEM images of 585nm, 605nm, and 655nm-emitting QDs are shown in Figure 1(a-c), respectively. Image analysis of $\mathrm{N}>125$ particles of each particle type confirms the well-known red-shift in emission peak wavelength with overall particle size, ${ }^{[33]}$ shown in Figure 1(d). Interestingly, however, the average aspect ratio (defined as the ratio of maximum to minimum diameter) was highest for the QD605 samples, as shown in Figure 1(e). Elongated QDs exhibit a slightly red-shifted fluorescence peak as compared to spherical particles of comparable volume ${ }^{[41]}$ and thus aspect ratio is another parameter which can be used to "tune" the QD emission wavelength for specific applications. For all samples imaged, average particle diameter and aspect ratio values were statistically significant from each other with $\mathrm{p}<0.01$ in each case, as determined by analysis of variance (ANOVA). 


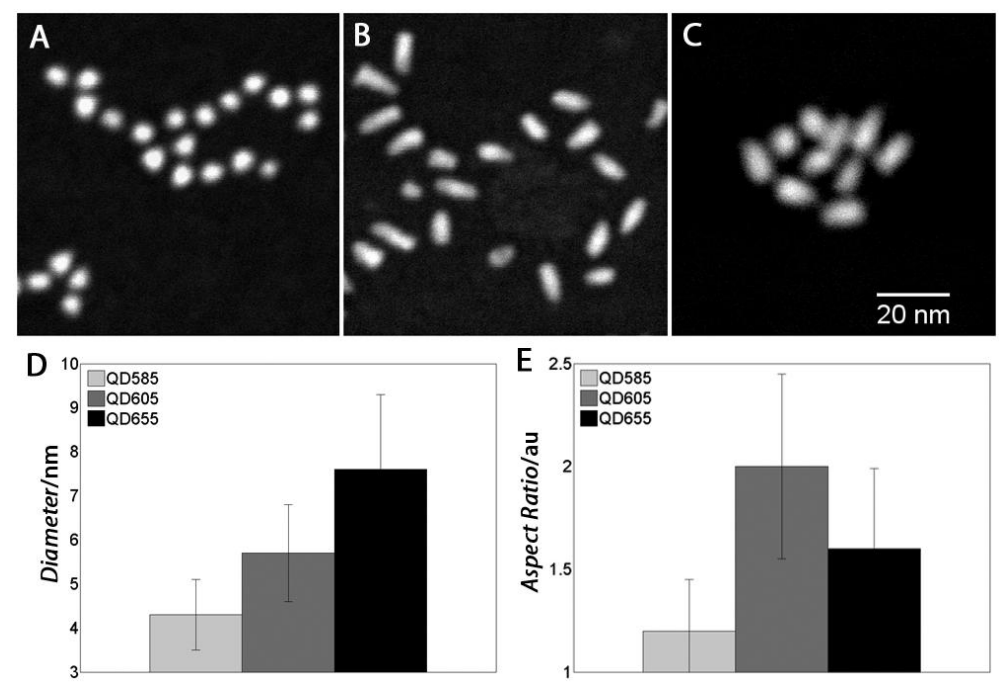

Figure 1. STEM images of quantum dots (QDs) with fluorescent emission peak maxima of 585nm (A), 605nm (B), and 655nm (C) were acquired using a Tecnai F-30ST TEM/STEM (FEI Company) operating at 300kV. (D) Subsequent image analysis of $\mathrm{N}>125$ particles reveals average particle diameters of $4.3 \mathrm{~nm}, 5.7 \mathrm{~nm}$, and $7.6 \mathrm{~nm}$ for the $585 \mathrm{~nm}-, 605 \mathrm{~nm}-$, and $655 \mathrm{~nm}$-emitting QDs. (E) The average particle aspect ratio, however, was found to be highest for the 605nm-emitting QDs at 2.0, vs. 1.2 and 1.6 for the 585nm- and 655nm-emitting QDs, respectively. All average particle diameter and aspect ratio values were statistically significant from each other with $\mathrm{p}<0.01$ in each case.

\subsubsection{Particle Diffusion in the Cellular Membrane}

Optical microscopy and imaging methods provide a convenient platform to non-destructively probe the dynamics in living biological systems. To image QD behavior in living cells with high spatial and temporal resolution, we employed total internal reflectance fluorescence (TIRF) imaging. The evanescent wave produced via oblique laser illumination on the sample results in selective excitation of fluorophors within a 100-200nm axial distance from the glass coverslip; this technology is fully described elsewhere. ${ }^{[37]}$ Because of the unique capabilities of TIRF, QD behavior can be optically constrained to include only particles that are very close to the cell membrane, resulting in an effective axial optical sectioning capability below the diffraction limit. 
Samples for TIRF imaging were prepared by culturing RBL cells to near confluence, followed by non-enzymatic harvesting (Cell Stripper®, Cell-Gro) and re-suspension at approximately $10^{5}$ cells $\mathrm{mL}^{-1}$. Aliquots of each QD type were added at a final concentration of $1 \mathrm{nM}$ to each of three corresponding cell samples, and allowed to mix for approximately 30 minutes at $4^{\circ} \mathrm{C}$. Incubation at low temperature suppresses internalization of particles into the cell cytoplasm due to decreased membrane fluidity, thus ensuring a sufficient particle population for imaging on the cell surface. Images from $\mathrm{N}=3-5$ cells for each particle type were acquired at 10-50 Hz, and subsequently analyzed using a single-particle tracking algorithm implemented in NIH ImageJ. ${ }^{[42]}$

Example single-particle trajectories are shown for QD585, QD605, and QD655 in Figure 2(ac), respectively. Trajectories represent the path taken by QD over a 3-5 second time-span within the cell membrane. To derive the average diffusion coefficient over this period, at least 190 trajectories from each QD type (representing at least 3 cells for each particle population) were calculated, and the mean-squared displacement $(M S D)$ within the membrane as a function of time lag $(\Delta t)$ was plotted. The resulting trace was then fit to a 2-D anomalous diffusion model ${ }^{[43]}$, shown in equation (1):

$$
M S D=4 D \Delta t^{\alpha}
$$

Where $D$ is the diffusion constant, and $\alpha$ is a parameter indicating whether a particle is undergoing diffusion that is non-linearly related to time. An $\alpha$ value greater than one indicates active transport of the particle, while a value less than one indicates hindered motion, for example, due to corralling within the membrane. The resulting distributions of diffusion coefficients $(D)$ are shown in Figure 2(d-f) for QD585, QD605, and QD655, respectively, and indicate a range of values spanning several orders of magnitude (note that the histograms are plotted on a logarithmic scale on the x-axis). Further analysis (not shown) indicates a clear positive correlation between diffusion constant (D) and alpha value ( $\alpha$ ). This large range in diffusivity is to be expected given the heterogeneous nature of the plasma membrane. Nevertheless, overall differences between each QD type are apparent, shown in Figure 2(g). Evaluation of mean diffusion coefficients reveals that QD605 particles, on average, diffuse at a rate nearly an order of magnitude less than QD585, and nearly 5-fold 
less than for QD655. Uncertainty values in Figure 2(g) are shown in terms of standard error of the mean, due to the fact that calculated individual diffusion coefficients are averaged over the entire particle trajectory in each calculation. However, each particle's diffusion coefficient values were statistically distinguishable from each other with $\mathrm{p}<0.01$. While these differences in diffusion behavior cannot be explained solely by differences in particle size, QD aspect ratio (Figure 1e) does appear to be inversely correlated with diffusion coefficient, suggesting that the $605 \mathrm{~nm}$-emitting particles (those with highest aspect ratio) are the least mobile within the cell membrane as compared to more spherical particles.
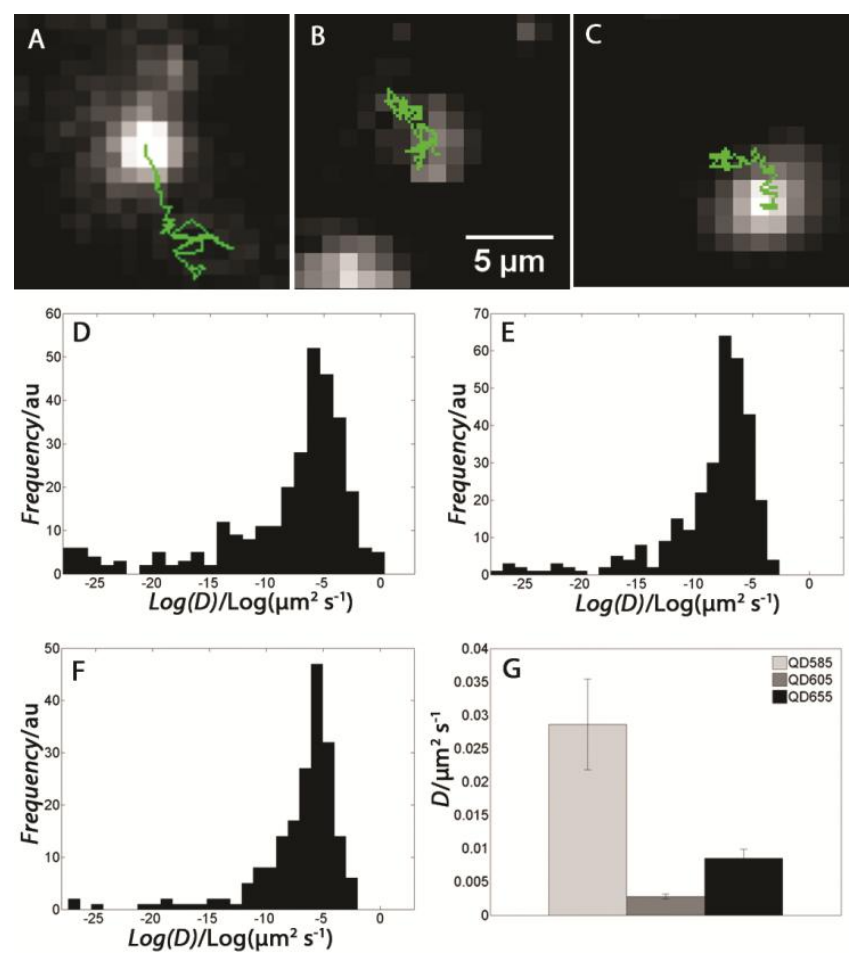

Figure 2. Single QD tracking within the cell membrane. (A-C) Example particle trajectories over a 3-5 second time period are shown for 585nm-, 605nm-, and 655nm-emitting QDs, respectively. The mean-squared displacement of each trajectory was calculated as a function of time-lag, and fit to a 2D anomalous diffusion model to extract the average diffusion coefficient for each particle. (D-F) The diffusion behavior of 200-300 particles of each type was evaluated and plotted as a histogram for $585 \mathrm{~nm}-$, $605 \mathrm{~nm}$-, and $655 \mathrm{~nm}$-emitting QDs, respectively. Note the log-scale on the $\mathrm{x}$-axis for each plot, indicating a large diversity in particle behavior. (G) The average diffusion coefficients for each particle type (with uncertainties expressed as standard error of the mean) reveal that the $605 \mathrm{~nm}$-emitting QDs diffuse an order of magnitude slower that the 585nm-emitting QDs, and nearly 5-fold slower 
than the 655nm-emitting QDs $(\mathrm{p}<0.01)$. This behavior mirrors the average aspect ratio measured for each particle type (see Figure 1E).

\subsubsection{Particle Uptake Kinetics}

To characterize the uptake kinetics of QDs into RBL cells, the same samples described above were imaged using TIRF microscopy under the same conditions as described previously; however imaging was conducted over a longer time span. Images were acquired at intervals of 3-5 seconds for 45-60 minutes. To prevent any potential QD photobleaching during these extended experiments, an electronic shutter (Ealing) was used to ensure that the samples were not illuminated except during image acquisition via voltage triggering from the EMCCD detector. Control samples consisting of QDs on a glass substrate (not shown) were also imaged under identical imaging conditions, and were found to maintain their full brightness throughout the same imaging period. In addition, we utilized a 532nm long-pass filter during imaging to accommodate any potential time-dependant blue-shifting of QD fluorescence emission, which has been reported previously. ${ }^{[44]}$ Figure 3(a) shows a series of TIRF images spanning 45 minutes of a representative RBL cell exposed to QD605. As particles are internalized by the cell, they are transported away from the evanescent TIRF excitation field, and are thus not detectable, resulting in an overall decrease in fluorescence signal. Because the evanescent field in the TIRF microscope typically decays to near-zero within $100-150 \mathrm{~nm}$ of the cell membrane ${ }^{[37]}$, the effective axial resolution is greater than the traditional diffraction limit, thereby improving the accuracy of our particle uptake measurements as compared to traditional confocal microscopy.

Measurements of uptake kinetics were performed for each QD type, and repeated for 3-5 cells (each containing >100 particles). For each measurement, the total image intensity (with background offset removed) was plotted as a function of time, with example traces shown in Figure 3(b-d). These plots illustrate the overall signal intensity decrease as particles are internalized by the cell, and were each fit to a normalized exponential decay model to extract a characteristic uptake time constant. Average decay time values for each QD type are shown in Figure 3(e), and also show a correlation with particle shape, with the highest aspect ratio particles (QD605) having the longest average characteristic internalization time at approximately 7 minutes, significantly longer $(p<0.01)$ than the corresponding values for 
both the QD585 and QD655, which averaged 2-4 minutes. We confirmed the presence of internalized QDs (not shown) by switching the TIRF microscope to epi-illumination mode, thereby rendering the entire cell volume visible.
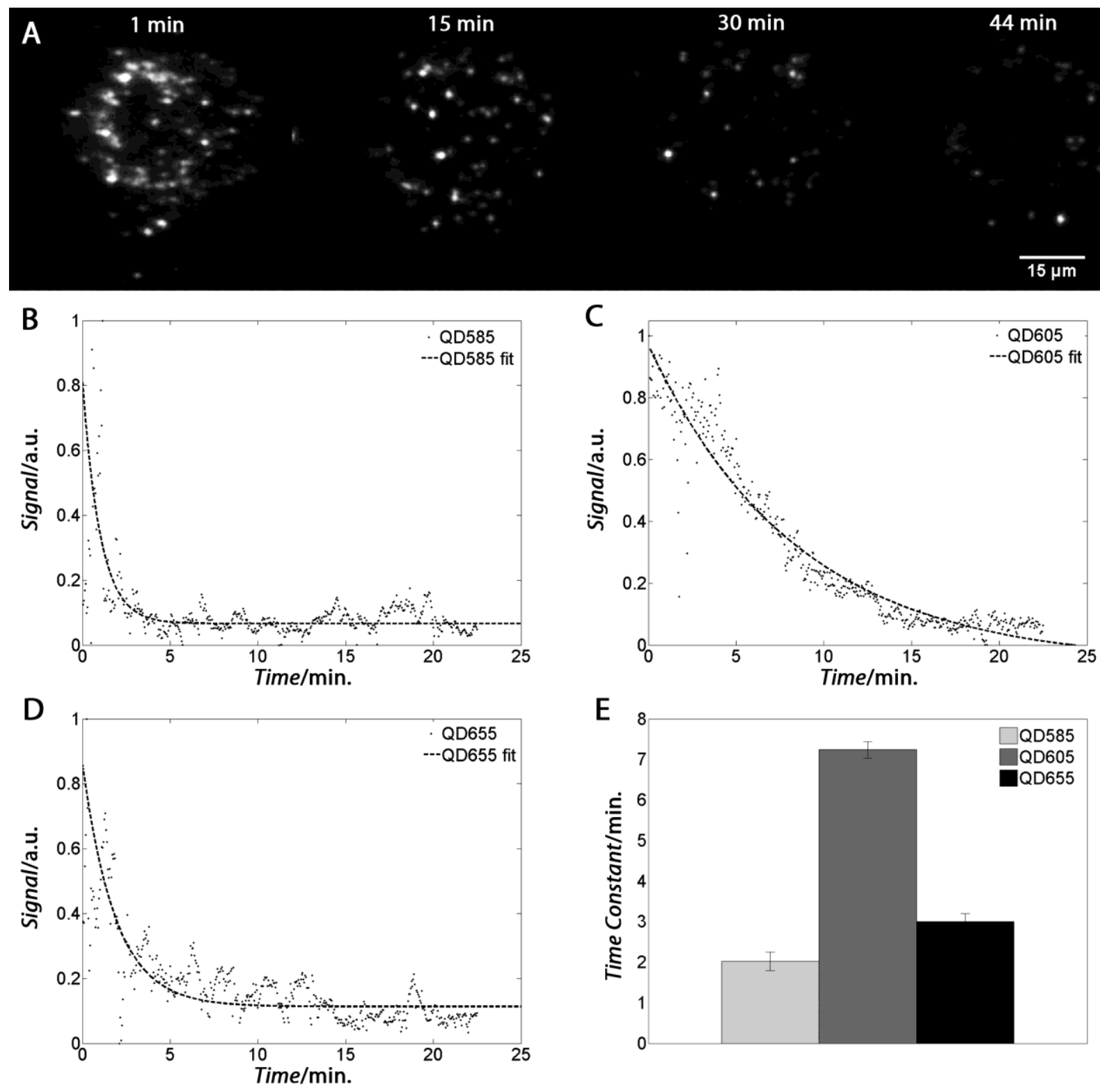

Figure 3. TIRF imaging to monitor QD uptake into RBL cells. TIRF images of RBL cells exposed to QDs were acquired at 3 second intervals for 45-60 minutes. (A) Example images showing uptake of $605 \mathrm{~nm}$-emitted QDs over 45 minutes. Note the overall signal intensity decreases over time as particles are internalized, thus moving beyond the 100-150nm TIRF evanescent field. (B-D) Total signal intensity (with background removed) was plotted for $585 \mathrm{~nm}-, 605 \mathrm{~nm}-$, and $655 \mathrm{~nm}$-emitting QDs, respectively (indicated by solid markers). A 
single exponential decay model was fit to the data (shown by dashed line), and a characteristic time constant was derived. (E) Average decay constants for each QD type, averaged over 3-5 cells, indicate that the 605nm-emitting QDs reside in the cell membrane, on average, for approximately 7 minutes, significantly longer $(\mathrm{p}<0.01)$ vs. the $2-3$ minutes for the $585 \mathrm{~nm}$ - and $655 \mathrm{~nm}$-emitting QDs.

\subsubsection{Particle Partitioning in the Cell Membrane}

We hypothesized that the apparent discrepancies in membrane behavior among each QD type may be in part due to their binding of different domains within the plasma membrane. To test this, we exposed RBL cells to all three QD types simultaneously and imaged samples using a custom-built hyperspectral confocal fluorescence (HCF) microscope. ${ }^{[38-39]}$ This instrument is advantageous over conventional fluorescence confocal imaging due to its ability to capture a complete, 512-channel fluorescence spectrum from each pixel within the image. When used in combination with multivariate curve resolution (MCR) algorithms, the concentration of multiple emitting fluorophors within the sample can be ascertained within each diffraction-limit spot size. Further, MCR permits identification of the number of emitting species in a sample as well as their relative concentration all without the need for $a$

priori information such as pure component reference spectra. ${ }^{[45-47]}$ These capabilities allow accurate identification of the relative abundance of each QD at every pixel in the microscope field of view, despite any spectral overlap present in the particles' fluorescence emission or the background fluorescence from the cell.

We concurrently exposed cells to a lysosome-specific dye (LysoTracker Yellow, Invitrogen). This enabled consideration of membrane-associated QDs separately from those sequestered in lysosomal vesicles by initially segmenting image pixels that were co-localized with the LysoTracker dye from the total signal. Figure 4(a) shows pure component spectra derived from MCR analysis of the HCF images of RBL cells labeled with all three QD types, as well as the Lysosome-specific dye. All spectra agree well with manufacturer data. Figure 4(b) shows an example RGB color overlay indicating the location and relative abundance of each QD in the cell, with QD585 in blue, QD605 in green, and QD655 in red. This image is a confocal slice taken near the equator of the cell. Note the signal associated with QDs that are internalized in vesicles appears largely white in the image, indicating an approximately equal 
mixture of each particle type in these organelles. To highlight the membrane associated particles only, QD signal that was co-localized with the lysosome-specific dye (not shown in Figure 4) was subtracted from the original image (shown in Figure 4(c)). Closer inspection (Figure 4(d)), suggests that QDs are not homogenously distributed within the cell membrane, but occupy distinct regions. To further illustrate this effect, Figure 4(e) shows areas of the same cell where at least $95 \%$ of the total QD signal is represented by only a single QD type, with red, green, and blue corresponding to QD655, QD605, and QD585, respectively. Analysis of $\mathrm{N}=27$ cells reveals that of the total number of image voxels that contain membrane-associated particles (corresponding to an approximate volume of $0.01 \mu \mathrm{m}^{3}$ each), an average of $12 \%$ are occupied by only a single type, far above what would be expected for homogenously distributed particles.

A

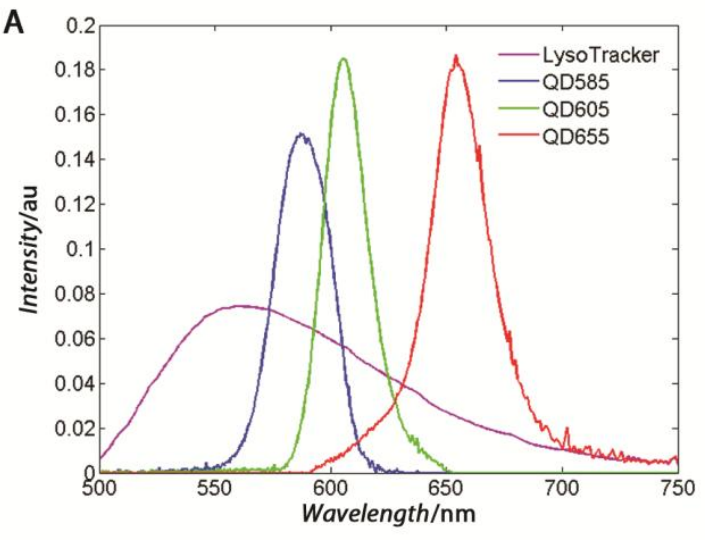

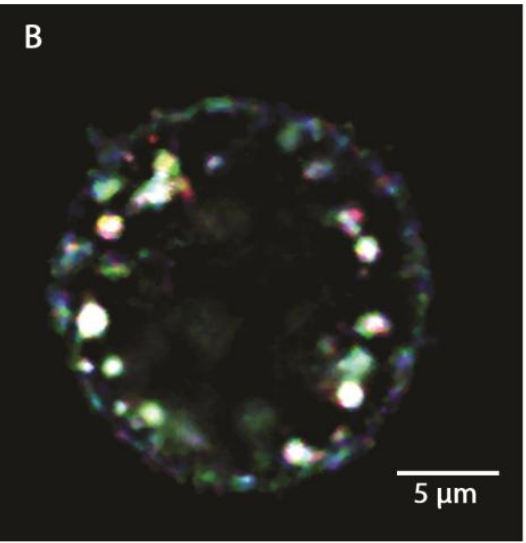

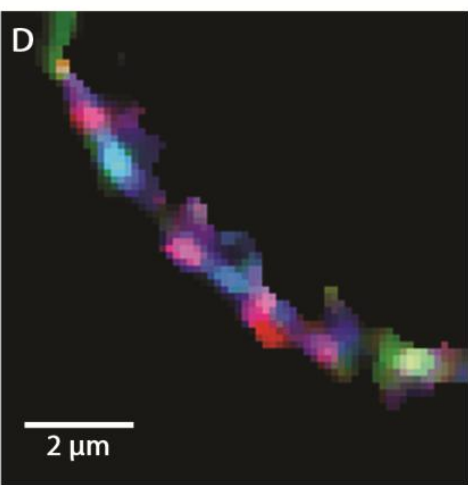

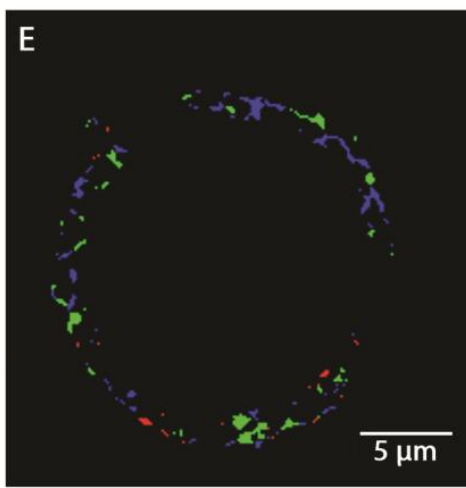

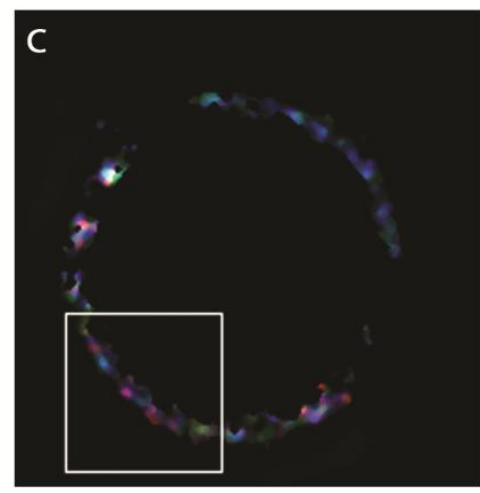

Figure 4. Hyperspectral fluorescence confocal (HCF) microscopy shows localization and abundance of all three QDs used in this study within a single cell. Figure (A) displays spectra of the three QDs as well as the lysosome-specific dye as derived from multivariate curve resolution (MCR) analysis of the hyperspectral image data. In (B), each QD type is shown for a representative cell, with QD585, QD605, and QD655 in blue, green, and red, respectively. QD signals that appear white, indicating roughly equal concentration of each 
particle type, are mainly localized with the lysotracker yellow signal (LysoTracker Yellow localization is shown in Figure 5). By only considering QD signals that were not colocalized with the dye, particles near the membrane can be examined separately (C). Closer examination of membrane-associated particles (area indicated by the white box) reveals that each QD type appears to occupy distinct regions in the cell membrane (D). In (E), a colorcoded image is shown of areas in the cell where at least 95\% of the total QD signal is attributable to a single particle type. Red, green, and blue correspond to QD655, QD605, and QD585, respectively. Analysis shows that, of the total cell membrane area that contains QDs, an average of $12 \%$ is represented by only a single particle type.

\subsubsection{Nanoparticle Sorting to Lysosomes}

By co-labeling cells with the lysosome-specific dye, we were also able to assess differences in endosomal sorting present between each QD type. Receptor-mediated endocytosis has been postulated to be the main entry route of nanoparticles into cells, with the ultimate destination being lysosomal degradation. ${ }^{[22,30,48]}$ To evaluate the ultimate fate of each QD type in our cell model, we considered both the QD signals associated with the cell membrane, as well as with lysosomes. As an example, three-color overlay images are shown depicting QD585, QD605, and QD655 co-localization with the LysoTracker dye in Figure 5(a-c), respectively. To generate these images, we computed the per-pixel co-localization of the signal from each QD type with that from the lysosome-specific dye, respectively. In these images, each respective QD signal is shown in green, while the lysosome dye is indicated in red. Areas where co-localization occurs, as defined by a minimum intensity threshold and ratio for each components' signal, are depicted in white. By computing the percentage of total QD signal that is co-localized with the Lysotracker dye, we were able to determine the overall fraction of QDs that are present in the cell's lysosomal vesicles. We observed considerable cell-to-cell variation in the total amount of QDs that were internalized (between 15-90\%). However, by normalizing the colocalization value for QD type by the mean value for the corresponding cell to compensate for cell to cell differences in overall QD internalization, we are able to assess relative differences in lysosomal sorting between particle types. For the $\mathrm{N}=27$ cells imaged, the lysosomal sorting shows a statistically significant $(\mathrm{p}<0.02)$ trend with increasing size, in contrast with the apparent shape-dependent behavior observed for QDs that are associated with the membrane. 


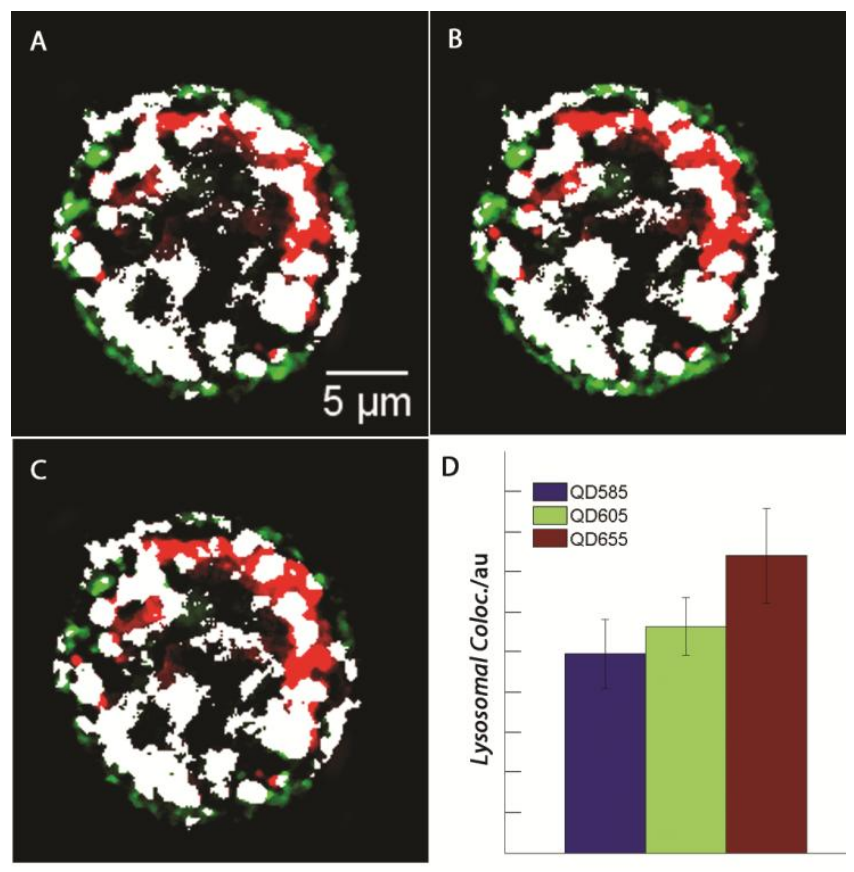

Figure 5. Lysosomal colocalization of each QD type. HCF microscopy of cells labeled with QD585, 685, and 655, along with a lysosome-specific dye (LysoTracker Yellow, Invitrogen), allows quantification of lysosomal co-localization of each particle type in a single cell. (A-C) shows co-localization images for QD585, 605, and 655, respectively. In each image, the respective QD signal is indicated in green, while the LysoTracker signal is shown in red. Areas where co-localization occurs, as defined by a minimum threshold and signal ratio, are shown in white. The total fraction of each QD that was colocalized with lysosomes was computed for $\mathrm{N}=27$ cells and varied widely from cell to cell. However, normalizing the data to adjust for cell-to-cell variations in overall uptake reveals relative differences in particle uptake. Analysis shows (D) that lysosomal uptake significantly increases with particle size (p $<0.02$ ).

\subsection{Conclusions}

The effect of nanoparticle shape and size on cellular uptake has been examined both in the case of gold particles in epithelial cells, ${ }^{[27]}$ as well as recently in the case of CdTe nanocomposites in macrophages. ${ }^{[19]}$ Both studies indicate that as particle shape deviates substantially from the spheriodal case, uptake is suppressed. However, Chan and colleagues also found that an optimal size of about 40nm exists for uptake of gold nanoparticles. Our studies of CdSe particles in RBL cells are consistent with these observations. Importantly, our novel use of TIRF and HCF microscopy also allows us to provide further insight by examining shape and size effects simultaneously on particle behavior in the cell membrane, 
as well as their ultimate fate within the cell's endocytotic machinery. Overall, we show that particle size and shape both play roles at different stages in the cell's processing of QDs. Our data suggest that higher aspect ratio particles are more immobile in the cell membrane and are slower to be internalized by the cell. HCF microscopy suggests that this may be due to their preferential binding to distinct domains in the cell membrane. However, effects solely due to nanoparticle size cannot be ruled out, as there have been suggestions that nanoparticle radii of curvature may be critical for entry into cellular endosomes. ${ }^{[19,28]}$ Although the effect of particle shape on cell membrane binding and diffusion seems clear given this study and others, the underlying mechanism remains unclear. Given our observation that similarly sized and shaped QDs tend to cluster with each other in the cell membrane may simply indicate stronger inter-particle forces with materials of similar geometry, or could indicate preferential binding between certain membrane domains and particular particle shapes. We anticipate that future work will involve determining how particle geometry may determine initial cell membrane binding behaviors.

A thorough understanding of nanoparticle-cell interactions will be critical to determining mechanism(s) of toxicity. For instance, while studies by Drezek and colleagues suggest that QD degradation in lysosomes and the release of heavy metal ions is primarily responsible for cell death, ${ }^{[22]}$ others have shown that lipid peroxidation by QDs and the resulting cell membrane disruption can also cause apoptosis. ${ }^{[23]}$ Based on our data, we speculate that particle size and shape may ultimately determine which toxicity mechanism predominates. Overall, we anticipate that studies examining cell-nanoparticle interactions in depth will ultimately result in better informed nanomaterial designs with considerations towards minimization of unintended physiological and environmental consequences.

\subsection{Experimental Section}

\section{Quantum Dot Characterization}

Electron microscopy images of CdSe QDs (with fluorescence emission peaks of 585, 605, and $655 \mathrm{~nm}$, respectively) (Invitrogen) were acquired with an field emission transmission electron microscope (TEM)/scanning transmission electron microscope (STEM) (Tecnai F30ST, FEI Company) operating at 300kV. TEM specimens were prepared by dispersing 
nanoparticles onto carbon-coated $\mathrm{Cu}$ TEM grids and STEM images were acquired with an annular dark-field detector which provides image contrast proportional to the square of the atomic number $\left(\mathrm{Z}^{2}\right)$, as well as projected thickness. ${ }^{[40]}$

\section{Cell Culture and Exposure to Nanoparticles}

Rat Basophilic Leukemia Cells (RBL-2H3, ATCC) were cultured at $37^{\circ} \mathrm{C}$ and $5 \% \mathrm{CO}_{2}$ with Modified Eagle Medium (MEM-alpha, Gibco), harvested using non-enzymatic cell-stripper (Mediatech), and re-suspended $\left(10^{5}\right.$ cells $\left.\mathrm{mL}^{-1}\right)$ in Hank's balanced salt solution (1x HBSS, Gibco). For TIRF experiments, CdSe QDs (Invitrogen) with fluorescence emission peaks at 585,605 , and $655 \mathrm{~nm}$, respectively, were then added $(1 \mathrm{nM})$ to the three corresponding cell suspensions. Cells and QDs were incubated for 30 minutes at $4{ }^{\circ} \mathrm{C}$ to allow cell-nanoparticle binding, while initially suppressing particle internalization. Following incubation, cells were subsequently washed in cold MEM and placed in an open-dish imaging chamber (Harvard Apparatus) and heated to $37^{\circ} \mathrm{C}$ on the microscope (detailed below). To determine particle fate within the cell after internalization, cells were cultured as described above, and exposed to all three QD types (1nM each) simultaneously at $37^{\circ} \mathrm{C}$ for 15 minutes. Cells were then concurrently exposed to a lysosome-specific fluorescent dye (1nM, Lysotracker Yellow, Invitrogen) for an additional 15 minutes. Cells were subsequently washed as before and placed on a coverslip for imaging.

\section{Total Internal Reflectance Fluorescence (TIRF) Microscopy}

Cell samples were placed on a custom built, objective-based (60x, 1.45NA) TIRF microscope (IX-71, Olympus) and particle uptake was then allowed to occur by heating samples to $37^{\circ} \mathrm{C}$ while on the microscope. Temperature was maintained via both objective and stage heaters (Harvard Apparatus). Samples containing cells labeled with either 585, 605 , or $655 \mathrm{~nm}$ emitting QDs, were illuminated using a $488 \mathrm{~nm}$ solid state laser (Spectra Physics) at low power (approximately $0.5 \mathrm{~mW}$ ), and imaged through a 532nm long-pass filter (Semrock) while in TIRF conditions. Images were captured using an electron-multiplied charge-coupled device (EMCCD) (iXon, Andor Technologies, Ltd.), capable of acquiring up to 50 frames per second in frame transfer mode for a 128 x 256 pixel region of interest on the EMCCD. The EMCCD was operated at a temperature of $-100^{\circ} \mathrm{C}$ with a gain index of 100 . 
Image sequences were initially taken at high temporal resolution $(<0.1 \mathrm{~s})$ to monitor particle diffusion in the membrane. Subsequently, time-lapse imaging was performed at 3-5 seconds per frame for 45-60 minutes in order to monitor QD uptake kinetics. Because QDs are no longer detectable in TIRF after they are internalized $>150 \mathrm{~nm}$ from the cell membrane, ${ }^{[37]}$ uptake behavior was measured via the apparent decrease in signal over time. Control samples consisting of each QD type on a glass substrate were imaged to ensure that no significant photobleaching occurred under the imaging conditions used.

\section{Hyperspectral Confocal Fluorescence Microscopy}

A custom-built hyperspectral confocal microscope ${ }^{[38-39]}$ was used to assess the distribution in the plasma membrane, as well as lysosomal co-localization of each of the three QDs used in this study. This system utilizes a 488nm solid state laser excitation source (Spectra Physics), and collects a fluorescence emission spectrum spanning 490-800nm from each diffractionlimited spot in the field of view. Excitation light is focused via a 60x, 1.4 NA objective and scanned across the sample using a combination of a galvanometer-controlled mirror (in the ydirection) and a piezo controlled stage (in the x-direction). The fluorescence signal is isolated via a rugate notch filter (Edmund Industrial Optics) and wavelength-dispersed through a custom-fabricated, achromatic prism. A pinhole in front of the prism spectrometer ensures confocality of the images. The dispersed signal is then detected via an EMCCD (iXon, Andor). For this study, the system was set to collect 4150 spectra per second, thus enabling acquisition of a 15-slice hyperspectral confocal image stack (consisting of over $3 \times 10^{8}$ data points) in less than 5 minutes or a single optical section though a cell in approximately 10 sec.

\section{Data Analysis}

All STEM and TIRF images were analyzed in NIH ImageJ and Matlab. STEM images of QDs were analyzed via standard particle analysis algorithms to determine mean equivalent diameter and aspect ratio. At least 150 particles of each type were considered in the analysis. TIRF images were subjected to single particle tracking algorithms ${ }^{[42]}$ to determine membrane diffusion constants, based on an anomalous diffusion model. In addition, we have utilized a custom developed multivariate curve resolution (MCR) algorithm implemented in a GUI- 
based software platform to analyze the hyperspectral confocal fluorescent images. ${ }^{[45-47]} \mathrm{MCR}$ represents an attractive analysis method, as it is capable of identifying multiple fluorescent species in a sample with minimal a priori information. ${ }^{[45-46]}$ Thus, using robust constraints

and Poisson and read noise weighting ${ }^{[47]}$ we were able to identify and quantify the presence of all three QD types, as well as the lysosome-specific dye within a single cell. We used this information to compute relative abundance of each QD as well as the lysosomal colocalization of each QD type using subsequent image analysis in Matlab.

\subsection{References}

[1] Project on Emerging Nanotechnologies, can be found under http://www.nanotechproject.org, 2010.

[2] A. Z. Wang, F. Gu, L. Zhang, J. M. Chan, A. Radovic-Moreno, M. R. Shaikh and O. C. Farokhzad, Expert Opin. Biol. Ther. 2008, 8, 1063-1070.

[3] O. C. Farokhzad, Expert Opin. Drug Del. 2008, 5, 927-929.

[4] K. Cho, X. Wang, S. Nie, Z. Chen and D. M. Shin, Clin. Cancer Res. 2008, 14, 13101316.

[5] C. Corot, P. Robert, J.-M. Idée and M. Port, Adv. Drug Del. Rev. 2006, 58, 1471-1504.

[6] D. Sosnovik, M. Nahrendorf and R. Weissleder, Basic Res. Cardiol. 2008, 103, 122-130.

[7] K. Aslan, J. R. Lakowicz and C. D. Geddes, Curr. Opin. Chem. Biol. 2005, 9, 538-544.

[8] X. Michalet, F. F. Pinaud, L. A. Bentolila, J. M. Tsay, S. Doose, J. J. Li, G. Sundaresan, A. M. Wu, S. S. Gambhir and S. Weiss, Science 2005, 307, 538-544.

[9] J. Aaron, N. Nitin, K. Travis, S. Kumar, T. Collier, S. Y. Park, M. Jose-Yacaman, L. Coghlan, M. Follen, R. Richards-Kortum and K. Sokolov, J. Biomed. Optics 2007, 12, 034007.

[10] K. Sokolov, M. Follen, J. Aaron, I. Pavlova, A. Malpica, R. Lotan and R. RichardsKortum, Cancer Res. 2003, 63, 1999-2004.

[11] S. Iijima Nature 1991, 354, 56-58

[12] C.-W. Lam, J. T. James, R. McCluskey and R. L. Hunter, Toxicol. Sci. 2004, 77, 126134.

[13] C. A. Poland, R. Duffin, I. Kinloch, A. Maynard, W. A. H. Wallace, A. Seaton, V. Stone, S. Brown, W. MacNee and K. Donaldson, Nat Nano 2008, 3, 423-428. 
[14] N. Lewinski, V. Colvin and R. Drezek, Small 2008, 4, 26-49.

[15] C. M. Sayes, J. D. Fortner, W. Guo, D. Lyon, A. M. Boyd, K. D. Ausman, Y. J. Tao, B. Sitharaman, L. J. Wilson, J. B. Hughes, J. L. West and V. L. Colvin, Nano Lett. 2004, 4, 1881-1887.

[16] N. Pernodet, X. Fang, Y. Sun, A. Bakhtina, A. Ramakrishnan, J. Sokolov, A. Ulman and M. Rafailovich, Small 2006, 2, 766-773.

[17] A. M. Smith, X. Gao and S. Nie, Photochem. Photobiol. 2004, 80, 377-385.

[18] R. Hardman, Environ Health Perspect. 2005, 114, 165-172.

[19] Z. Lu, Y. Qiao, X. T. Zheng, M. B. Chan-Park and C. M. Li, Med. Chem. Commun.

\section{0}

[20] J. Ryman-Rasmussen, J. Riviere and N. Monteiro-Riviere, J. Invest. Dermatol. 2007, $127,143-153$.

[21] J. P. Ryman-Rasmussen, J. E. Riviere and N. A. Monteiro-Riviere, Nano Lett. 2007, 7, 1344-1348.

[22] E. Chang, N. Thekkek, William W. Yu, Vicki L. Colvin and R. Drezek, Small 2006, 2, 1412-1417.

[23] A. Choi, S. J. Cho, J. Desbarats, J. Lovric and D. Maysinger, Journal of Nanobiotechnol. 2007, 5, 1.

[24] J. Lovrić, H. S. Bazzi, Y. Cuie, G. R. A. Fortin, F. M. Winnik and D. Maysinger, J. Mol. Med. 2005, 83, 377-385.

[25] J. Lovric, S. J. Cho, F. M. Winnik and D. Maysinger, Chem. \& Biol. 2005, 12, 1227 1234.

[26] Y. Xiao, S. Forry, X. Gao, R. D. Holbrook, W. Telford and A. Tona, J. Nanobiotechnol. 2010, 8, 13 .

[27] B. D. Chithrani, A. A. Ghazani and W. C. W. Chan, Nano Lett. 2006, 6, 662-668.

[28] W. Jiang, Y. S. KimBetty, J. T. Rutka and C. W. ChanWarren, Nat. Nano. 2008, 3, 145150.

[29] M. E. Akerman, W. C. Chan, P. Laakkonen, S. N. Bhatia and E. Ruoslahti, Proc. Nat. Acad. Sci. USA 2002, 99, 12617-12621.

[30] A. P. Alivisatos, W. Gu and C. Larabell, Annual Rev. Biomed. Engr. 2005, 7, 55-76. 
[31] W. C. Chan, D. J. Maxwell, X. Gao, R. E. Bailey, M. Han and S. Nie, Curr. Opin. Biotechnol. 2002, 13, 40-46.

[32] W. C. Chan and S. Nie, Science 1998, 281, 2016-2018.

[33] X. Gao, W. C. W. Chan and S. Nie, J. Biomed. Optics 2002, 7, 532-537.

[34] X. Gao, L. Yang, J. A. Petros, F. F. Marshall, J. W. Simons and S. Nie, Curr. Opin. Biotechnol. 2005, 16, 63-72.

[35] X. Gao, Y. Cui, R. Levenson, L. Chung and S. Nie, Nat. Biotechnol. 2004, 22, 969 976.

[36] E. L. Barsumian, C. Isersky, M. G. Petrino and R. P. Siraganian, Euro. J. Immunol. 1981, 11, 317-323.

[37] D. Axelrod, Traffic 2001, 2, 764-774.

[38] M. B. Sinclair, D. M. Haaland, J. A. Timlin and H. D. T. Jones, Appl. Optics 2006, 45, 6283-6291.

[39] W. F. J. Vermaas, J. A. Timlin, H. D. T. Jones, M. B. Sinclair, L. T. Nieman, S. W. Hamad, D. K. Melgaard and D. M. Haaland, Proc. Nat. Acad. Sci. USA 2008, 105, 40504055.

[40] P. G. Kotula and M. R. Keenan, Microscopy Microanal. 2006, 12, 538-544.

[41] X. Peng, L. Manna, W. Yang, J. Wickham, E. Scher, A. Kadavanich and A. P. Alivisatos, Nature 2000, 404, 59-61.

[42] I. F. Sbalzarini and P. Koumoutsakos, J. Struct. Biol. 2005, 151, 182-195.

[43] J.-P. Bouchaud and A. Georges, Phys. Rep. 1990, 195, 127-293.

[44] Y. Zhang, J. He, P.-N. Wang, J.-Y. Chen, Z.-J. Lu, D.-R. Lu, J. Guo, C.-C. Wang and W.-L. Yang, J. Am. Chem. Soc. 2006, 128, 13396-13401.

[45] D. M. Haaland, J. A. Timlin, M. B. Sinclair, M. H. V. Benthem, M. J. Martinez, A. D. Aragon and M. Werner-Washburne, Proc. SPIE 2003, 4959 , pp. 55-66.

[46] M. H. V. Benthem and M. R. Keenan, J. Chemometrics 2004, 18, 441-450.

[47] H. D. T. Jones, D. M. Haaland, M. B. Sinclair, D. K. Melgaard, M. H. Van Benthem and M. C. Pedroso, J. Chemometrics 2008, 22, 482-490.

[48] K.-i. Hanaki, A. Momo, T. Oku, A. Komoto, S. Maenosono, Y. Yamaguchi and K. Yamamoto, Biochem. Biophys. Res. Commun. 2003, 302, 496-501. 


\section{Induced IL-8 Response in Human Alveolar Basal Epithelial Cells Following Exposure to Gold and Silver Nanoparticles}

\subsection{Chapter Summary}

While gold (AuNP) and silver (AgNP) nanoparticles have been reported to cause a wide array of physiological effects (e.g., cytotoxicity, DNA damage, etc.), the toxicology of these NPs at occupational exposure levels remains unknown. Thus, we characterized the in vitro response of human adenocarcinomic alveolar basal epithelial cells (A549) to 20 and $60 \mathrm{~nm}$ AuNPs and AgNPs at expected levels of occupational exposure. Cytotoxicity, IL-6 secretion, and oxidative stress were not significantly affected by exposure to either AgNPs or AuNPs at occupational exposure levels. Differences in cellular responses to NP type and size were also not observed. Significant differences in the release of IL-8, however, were observed for cells exposed to occupational levels of $20 \mathrm{~nm}$ AgNPs and 20nm AuNPs, when compared against controls. Further data demonstrated that IL-8 secretion, but not cytotoxicity, is strongly dependent on both NP size and concentration (i.e., dose-dependency). Together these data suggest that occupational exposure to AgNPs and AuNPs may represent a lower risk than has been previously reported in the literature.

\subsection{Introduction}

Engineered nanomaterials exhibit a wide range of unique and emergent properties based upon their nanoscale size. For this reason, such materials, particularly nanoparticles (NPs) are being rapidly developed and increasingly used in a variety of commercial applications. For example, silver nanoparticles (AgNPs) are used in refrigerators and washing machines based on their antibacterial properties (Panacek et al., 2006; Pal et al., 2007). Nanomaterials such as carbon nanotubes have been used in a number of commercial products due to their high tensile strength and ultra-lightweight nature (Baughman et al., 2002; Smart et al., 2006). The functional understanding of the acute and chronic toxicological effects of engineered nanomaterials is currently lacking (Lewinski et al., 2008), and may represent a significant limitation to the continued pace of nanomaterial development and application. 
Work with gold and silver nanoparticles (AuNPs and AgNPs) has generated considerable information on their unique optical and biological properties (Maynard et al., 2006). For example, AuNPs have been used as "tags" to track single molecules (e.g., membrane-bound receptors), as gene delivery agents, and as optical biosensors (Sperling et al., 2008). As mentioned above, AgNPs have been widely explored as anti-microbial agents effective against a wide range of bacteria and fungi (Nabikhan et al., 2010; Dallas et al., 2011). While the unique physical and chemical properties of AgNPs and AuNPs have been well-studied, the toxicological properties of these NPs have been poorly characterized to date. Reasons for this lack of knowledge include but are not limited to differences in NP synthesis, capping agents, size and shape of the NPs, and type of cells used. A critical understanding of their toxicology, however, will likely be a crucial factor in continued and future applications of these NPs.

Ingestion, inhalation, and dermal contact represent the most likely routes of NP exposure (Oberdorster et al., 2005). Because deposition of inhaled particulates is size-dependent, inhaled NPs such as AgNPs and AuNPs are likely to have significant effects in the deep regions of the lung (Mohamed et al., 2011). For this reason, a number of studies with human lung epithelial cells have been performed with respect to NP-induced toxicity. Data from these studies, however, are quite conflicting and do not provide a fundamental understanding of how observed toxicological effects are correlated with the chemical and physical properties of NPs. Moreover, the levels of NPs used in these experiments are well beyond the expected level of exposure expected in an occupational setting. Thus, the objective of the current study was to develop an understanding of the toxicity and response of alveolar epithelial cells to occupational exposure levels of AuNPs and AgNPs.

\subsection{Materials and Methods}

\section{Cell Culture}

The human adenocarcinomic alveolar basal epithelial cell lines A549 (ATCC \#CCL-185) was propagated at $37^{\circ} \mathrm{C}, 5 \% \mathrm{CO}_{2}$ in $\mathrm{F}-12 \mathrm{~K}$ medium $+10 \%$ fetal bovine serum (FBS). Cell passages between 5 and 8 were used for all experiments. 
Nanoparticles - AuNPs and AgNPs

BioPure $^{\mathrm{TM}}$ silver (AgNPs) and gold (AuNPs) were purchased from NanoComposix Inc. (San Diego, CA). All NP suspensions were $1.0 \mathrm{mg} / \mathrm{mL}$ with lot-specific properties shown in Table 1. Only a single lot of each NP type was used for all experiments. Two sizes, 20 and $60 \mathrm{~nm}$, were used to characterize potential size-dependent effects. In addition, AuNPs and AgNPs were capped with citrate or tannic acid, respectively, providing a means for evaluating differences in surface chemistry. As a surrogate for the proteinaceous surface fluid of the airways, fetal bovine serum (FBS) was used to coat the NPs with a protein layer prior to cell exposure. In addition, pre-coating with FBS minimizes aggregation and agglomeration of the NPs. Protein coating was performed by dilution of NPs in 100\% FBS and then adding serumfree $\mathrm{F}-12 \mathrm{~K}$ media to yield a final concentration of $10 \%$ serum in the media.

Table 1: Physical and chemical properties of AgNPs and AuNPs.

\begin{tabular}{lcccc}
\hline & AgNP-20 & AgNP-60 & AuNP-20 & AuNP-60 \\
\hline Lot Number & EAW1091 & EAW1093 & EAW1060 & KAB0020 \\
Diameter (TEM) & $19.2 \mathrm{~nm}$ & $57.7 \mathrm{~nm}$ & $19.7 \mathrm{~nm}$ & $57.9 \mathrm{~nm}$ \\
Standard Deviation & $2.2 \mathrm{~nm}$ & $5.0 \mathrm{~nm}$ & $2.0 \mathrm{~nm}$ & $6.5 \mathrm{~nm}$ \\
Coefficient of Variation & $11.2 \%$ & $8.6 \%$ & $10.1 \%$ & $11.3 \%$ \\
Hydrodynamic Diameter & $\mathrm{n} / \mathrm{a}$ & $68.3 \mathrm{~nm}$ & $24.1 \mathrm{~nm}$ & $58.3 \mathrm{~nm}$ \\
Zeta Potential & $-36.8 \mathrm{mV}$ & $-43.8 \mathrm{mV}$ & $-47.2 \mathrm{mV}$ & $-45.7 \mathrm{mV}$ \\
Stock Particles/mL & $2.6 \times 10^{13}$ & $9.5 \times 10^{11}$ & $1.3 \times 10^{13}$ & $5.1 \times 10^{11}$ \\
pH of Solution & 4.9 & 5.1 & 5.4 & 7.1 \\
Particle Surface & Citrate & Citrate & Tannic Acid & Tannic Acid \\
Solvent & $2 \mathrm{mM}$ citrate & $2 \mathrm{mM}$ citrate & Water & Water \\
\hline
\end{tabular}

\section{Temporal responses to AuNP and AgNP exposure}

The effects of AuNP- and AgNP-exposure on A549 cells over time were evaluated separately. Each experimental group (AuNP or AgNP) represented a $2 \times 3 \times 3$ factorial design with two NP sizes (20 and $60 \mathrm{~nm})$, three concentrations $\left(0,1.6 \times 10^{6}\right.$, and $1.6 \times 10^{7}$ $\left.\mathrm{NPs} / \mathrm{cm}^{2}\right)$, and three treatment periods $(1,24$, and $48 \mathrm{hr})$. The NP concentrations were derived based on a model occupational aerosol containing $100,000 \mathrm{NPs} / \mathrm{cm}^{3}$. The average adult human breathes approximately 10 liters/min of air, resulting in a total inhalation of $\sim 4800 \mathrm{~L}\left(4,800,000 \mathrm{~cm}^{3}\right)$ per $8 \mathrm{hr}$ work day. Thus, an individual would inhale $\sim 4.8 \times 10^{11}$ NPs over this time, based on the model aerosol. NPs deposit well and generally are poorly 
cleared (Moller et al., 2008). Therefore, we assumed 100\% deposition, zero clearance, and random distribution over the $\sim 100 \mathrm{~m}^{2}$ of lung, resulting in an exposure level of $4.8 \times 10^{9}$ $\mathrm{NPs} / \mathrm{m}^{2}$ in the lung. To adjust for potential unevenness of distribution, this value was scaled by a factor of 10 , providing a lower exposure level of $4.8 \times 10^{10} \mathrm{NPs} / \mathrm{m}^{2}\left(4.8 \times 10^{6} \mathrm{NPs} / \mathrm{cm}^{2}\right)$ (Phalen et al., 2006). A second concentration, $4.8 \times 10^{7} \mathrm{NPs} / \mathrm{cm}^{2}$ was also used for these experiments.

A 96-well tissue culture plate was seeded with A549 cells at a density of 1 x $10^{4}$ cells/well. Twenty-four hours after seeding, the cells reached 80-90\% confluency. Media was aspirated and replaced with $200 \mu \mathrm{L}$ of media containing AuNPs or AgNPs at concentrations of $8 \times 10^{6}$ $\mathrm{NPs} / \mathrm{mL}$ or $8 \times 10^{7} \mathrm{NPs} / \mathrm{mL}$ to achieve exposures of $4.8 \times 10^{6}$ and $4.8 \times 10^{7} \mathrm{NPs} / \mathrm{cm}^{2}$, respectively. Negative controls consisted of F-12K media $+10 \%$ FBS. All treatments were performed in triplicate. At 1, 24, and $48 \mathrm{hr}$ post-addition, the media was removed, transferred to a low-protein binding 96-well plate, and frozen at $-80^{\circ} \mathrm{C}$ until processed. The cells were gently washed with phosphate-buffered saline (PBS), flash frozen, and stored at $-80^{\circ} \mathrm{C}$.

\section{Dose-dependent responses to AuNP and AgNP exposure}

To discern dose-dependent responses, A549 cells were exposed to concentrations of NPs ranging from $8 \times 10^{6}$ to $8 \times 10^{10}$ particles $/ \mathrm{mL}$. A 96-well tissue culture plate was seeded with A549 cells at a density of $1 \times 10^{4}$ cells/well, as detailed above. Media was removed and replaced with solutions of media containing of AuNPs or AgNPs at concentrations of $8 \times 10^{6}$, $8 \times 10^{7}, 8 \times 10^{8}, 8 \times 10^{9}$, and $8 \times 10^{10} \mathrm{NPs} / \mathrm{mL}$. Negative control samples consisted of cells exposed to F-12K media $+10 \%$ FBS. All treatments were performed in triplicate. Cell supernatant were removed, transferred, and frozen at $24 \mathrm{hr}$ post-addition, as described above. Cells were washed with PBS, and assayed for WST-1 activity as a measure of cell viability, as described below.

\section{Biochemical assays \& data analyses}

Cell viability was evaluated by WST-1 (1[2-(4-Iodophenyl)-3-(4-nitrophenyl)-5-(2,4disulfophenyl)-2H-tetrazolium]) reduction activity by viable cells into a formazan dye, which 
was measured using the Cell Proliferation Reagent WST-1 (Roche Applied Science Corp., Indianapolis, IN). Following a PBS wash, the WST-1 reagent was added, incubated until a color change was visible (15-30 min), and quantified using a Victor ${ }^{\mathrm{TM}}$ Multilabel Plate Reader. Data were analyzed at each time point with a Two-way Analysis of Variance (ANOVA). The Holm-Sidak test for mean separation was used for pair-wise comparisons when main effects or interactions were detected.

Inflammatory and oxidative stress responses were characterized by measuring levels of interleukin-6 (IL-6) and interleukin-8 (IL-8), and heme oxidase-1 (HO-1), respectively. Commercial enzyme-linked immunosorbent assays (ELISA) were used to quantify IL-6 and IL-8 (R\&D Systems, Inc., Minneapolis, MN), and HO-1 (Enzo Life Sciences, Inc., Farmingdale, NY). For IL-6 and IL-8, cell supernatants were brought to room-temperature and assayed according to manufacturer's protocols. For HO-1, frozen cells were lysed by the addition of room-temperature extraction reagent provided with the kit. Cell extracts were centrifuged, diluted, and assayed according to the manufacturer's protocol. BCA (bicinchoninic acid) protein assays (Thermo Scientific, Rockford, IL) were used to quantify cellular protein concentration according to manufacturer's recommendations. Data were analyzed using three-way ANOVA as follows. In the temporal response experiments, the independent variables were time, NP size, and concentration. For the dose-dependency data, the independent variables were concentration, NP type (AuNP or AgNP), and NP size. The Holm-Sidak test for mean separation was used for pair-wise comparisons when main effects or interactions were detected.

\subsection{Results \& Discussion}

\subsubsection{Temporal response to AuNPs and AgNPs}

Significant differences in IL-6 concentrations were not observed following exposure to AuNPs and AgNPs (Figure 1). Three-way interactions among NP size, concentration, and time were not significant $(\mathrm{P}>0.3)$ for either NP type, suggesting that IL-6 is not up-regulated in response to occupational levels of AgNPs and AuNPs. For both particle types, the levels of IL-6 in each treatment did increase over time (i.e., significant main effect; P < 0.001), which is likely due to continued secretion of the cytokine by the A549 cells. In addition, BCA 
assays for intracellular protein demonstrated an increase in the total protein across all treatment (data not shown), which is consistent with continued proliferation of cells over time. Previous studies indicated a similar lack of IL-6 response to AuNPs (15 nm diameter; 61 and $561 \mathrm{ng} \mathrm{Au} / \mathrm{cm}^{2}$ concentration) in triple co-cultures of A549 cells, human

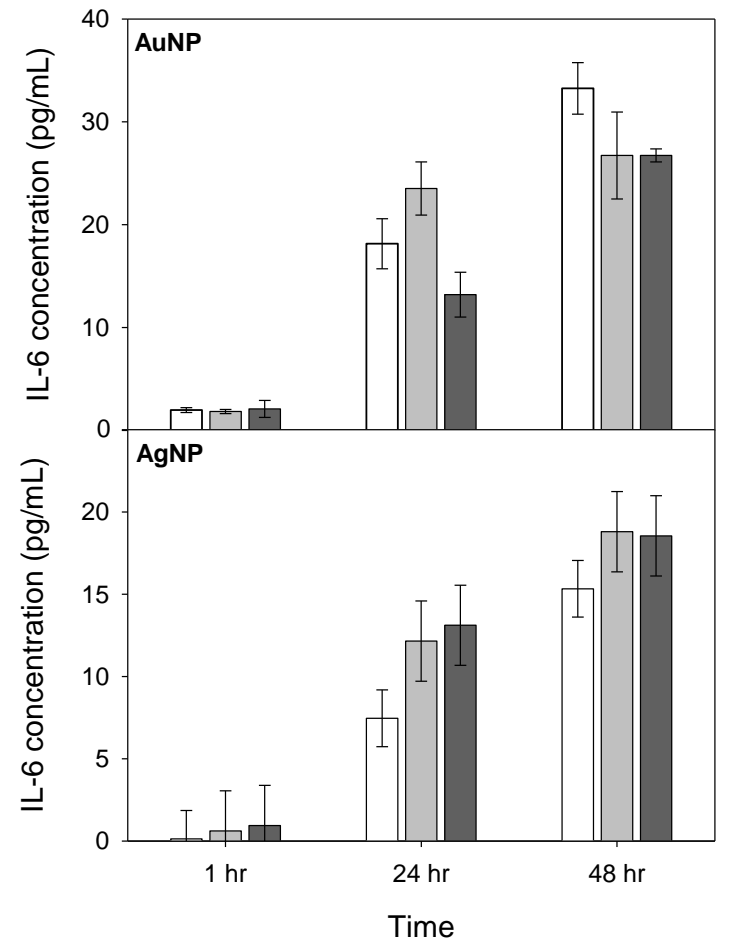

Figure 1: Secretion of IL-6 over time from A549 cells exposed to media (white), 20 $\mathrm{nm}$ NPs (light gray), or $60 \mathrm{~nm}$ NPs (dark gray). Error bars = standard error of the mean. macrophages, and human and dendritic cells (Brandenberger et al., 2010). Similarly, rat macrophages cells exposed to 15- and 30-nm AgNPs did not exhibit increased levels of IL6, but did display increases in other cytokines and chemokines (Carlson et al., 2008). Increased levels of IL-6 have been, however, reported in human epidermal keratinocytes (HEK) exposed to $0.34 \mu \mathrm{g} / \mathrm{mL}$ solutions of AgNPs (Monteiro-Riviere et al., 2010) and $20 \mathrm{nM}$ solutions of carboxylic acid-coated Qdots (Ryman-Rasmussen et al., 2007). Increased secretion of IL-8 has also been reported in bronchial epithelial cells (BEAS-2B) exposed to $>100 \mu \mathrm{g} / \mathrm{mL}$ AgNPs (Shin et al., 2008), and mouse macrophage cells exposed to AuNPs and AgNPs at concentrations >10 ppm (Yen et al., 2009). In all of these studies, the concentrations of NPs were substantially higher (i.e., >100x) than those used in our study, and considerably greater than what would be expected from occupational exposure. 
Secretion of IL-8 was significantly affected by exposure to AuNPs (Figure 2, top). While a three-way interaction was not observed $(P$ $>0.6$ ), a significant two-way interaction between size and time was observed for AuNPs $(\mathrm{P}<0.001)$. More specifically, levels of IL-8 levels were significantly different between the negative control and $20 \mathrm{~nm}$ treatment, and $20 \mathrm{~nm}$ and $60 \mathrm{~nm}$ AuNPs treatment at both 24 and $48 \mathrm{hr}$ post-exposure ( $\mathrm{P}<0.001)$. No differences were observed at $1 \mathrm{hr}$ post-exposure. Increases in IL-8 secretion have been reported for human mesenchymal stem cells (hMSCs) exposed to $\sim 15 \mathrm{~nm}$ AuNPs (Koller et al., 2010), as well as HEK cells exposed to $20 \mathrm{nM}$ solutions of carboxylic acid-coated Qdots (RymanRasmussen et al., 2007). However, no

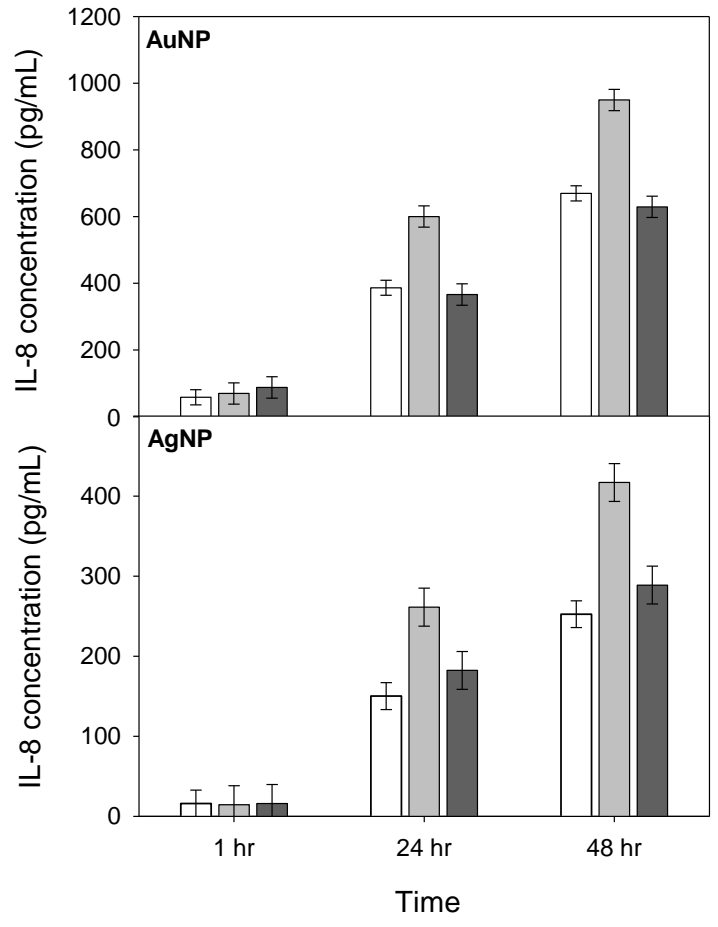

Figure 2: Secretion of IL-8 over time from A549 cells exposed to media (white), 20 nm AuNPs (light gray), or $60 \mathrm{~nm}$ AuNPs (dark gray). Error bars $=$ standard error of the mean.

change in IL-8 levels was observed following AuNP-exposure in a triple co-culture containing A549 cells, human macrophages, and human and dendritic cells (Brandenberger et al., 2010). A number of aspects between this report and our experiments may account for the observed differences in IL-8 response, including particle size ( $15 \mathrm{~nm}$ vs. $20 \& 60 \mathrm{~nm}$ ), surface ligand (citrate vs. tannic acid), NP pre-coating, NP concentration, and means of exposure.

A significant two-way interaction between size and time, with respect to levels of IL-8 (Figure 2, bottom), was observed for cells exposed to AgNPs ( $\mathrm{P}<0.01)$. Cells exposed to 20 $\mathrm{nm}$ AgNPs displayed significantly higher levels of IL-8 at 24 and $48 \mathrm{hr}$ post-exposure ( $\mathrm{P}<$ 0.01), as compared with the negative controls. IL-8 levels of cells exposed to $60 \mathrm{~nm}$ AgNPs were not significantly different from the negative controls $(\mathrm{P}>0.2)$. Together, these data suggest that only $20 \mathrm{~nm}$ AgNPs increase the secretion of IL-8 from A549 cells, similar to the 
observations for AuNPs. Increases in IL-8 secretion following exposure to AgNPs have also been reported in hMSCs (Kleinsasser et al., 2011), HEK cells (Monteiro-Riviere et al., 2010), and BEAS-2B cells (Shin et al., 2008). NPs used in these studies ranged from 20 to $100 \mathrm{~nm}$ in diameter, and were exposed at concentrations ranging from $0.5 \mathrm{ng} / \mathrm{mL}$ to 10 $\mu \mathrm{g} / \mathrm{mL}$. Effects on IL-8 secretion were reported only, however, at concentrations of AgNPs greater than $0.1 \mu \mathrm{g} / \mathrm{mL}$. By comparison, we observed increased IL-8 secretion at an AgNP $(20 \mathrm{~nm})$ concentration of $8 \times 10^{6} \mathrm{NPs} / \mathrm{mL}$, or approximately $0.3 \mathrm{ng} / \mathrm{mL}$, which is considerably lower than the values reported for other cell types.

Size by concentration interactions were also observed for both AuNPs and AgNPs. More specifically, the levels of IL-8 secretion differed between the low and high concentrations of $60 \mathrm{~nm}$ particles $(\mathrm{P}<0.02)$, irrespective of time. Similar differences based on concentration

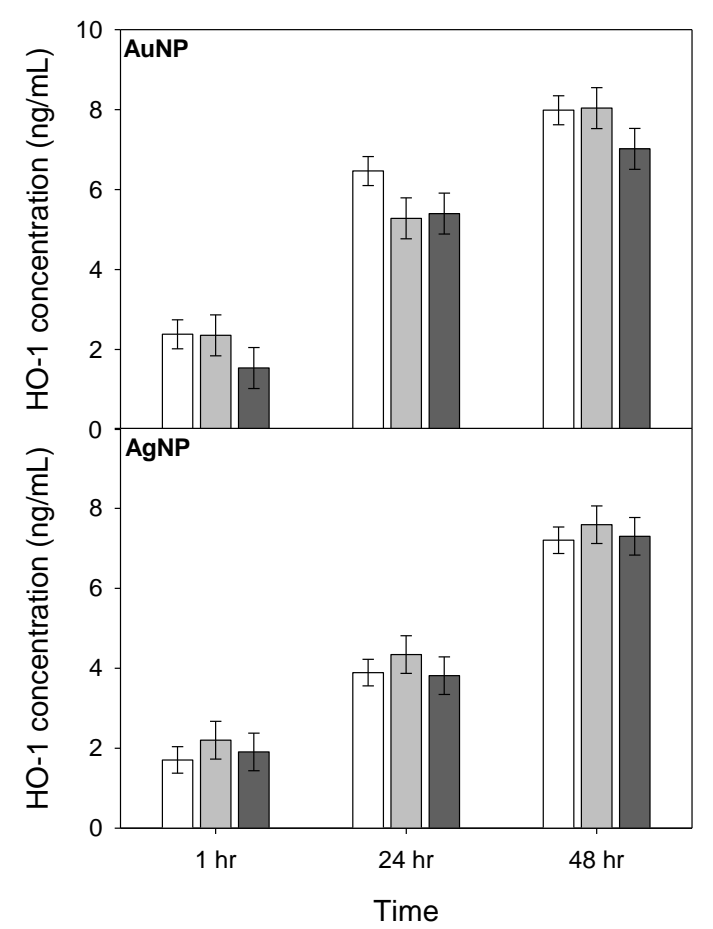

Figure 3: HO-1 concentrations over time from A549 cells exposed to media (white), $20 \mathrm{~nm}$ AuNPs (light gray), or $60 \mathrm{~nm}$ AuNPs (dark gray). Error bars = standard error of the mean. were not observed for $20 \mathrm{~nm}$ AuNPs or AgNPs. While $60 \mathrm{~nm}$ NPs did not significantly affect IL-8 concentrations, as noted above, these data suggest that the lack of effect may be concentration dependent. Further experimental data and discussion of this point are presented below.

Changes in oxidative stress, as characterized by HO-1 levels, were not observed due to NP exposure (Figure 3). For both AuNPs and AgNPs, three-way interactions among size, concentration, and time were not significant $(P>0.16)$. A significant time-dependency (i.e., main effect) was observed for both NP types $(\mathrm{P}<0.001)$, which is likely due to continued proliferation of the A549 cells, as noted above. A lack of oxidative stress (HO1) was reported previously for AuNPs 
(Brandenberger et al., 2010), consistent with our observations at lower concentrations of larger AuNPs. Up-regulation of HO-1 gene expression in HeLa, however, has been reported in response to AgNPs (5 - $10 \mathrm{~nm}$ diameter) at a concentration greater than $1 \mu \mathrm{g} / \mathrm{mL}$. In our work, changes in HO-1 levels were not observed for AgNPs at occupational concentrations. Oxidative stress has been suggested as a key indicator of nanomaterial-associated hazards (Nel et al., 2006; Stone and Donaldson, 2006; Mohamed et al., 2011). Based on this presupposition, our data indicate that occupational exposure to AuNPs and AgNPs present a relatively low hazard with respect to cellular cytotoxicity.

\subsubsection{Dose-dependent response in WST-1 and IL-8}

Neither AgNPs nor AuNPs exposure induced cytotoxic effects in A549 cells over the tested exposure range (Figure 4, top). No significant main effects or interactions were observed for WST-1 activity of cells following NP exposure $(\mathrm{P}>0.1)$. Moreover, no differences in WST-1 activity were observed between the two NP types. In addition to difference in the metal composition ( $\mathrm{Au}$ versus $\mathrm{Au}$ ), the NPs were capped with different surface ligands (i.e., citrate for AgNPs and tannic acid for AuNPs). Thus, the data also suggest that neither surface ligand induced significant toxicity. Prior reports on the toxicity of AuNPs in A549 cells present widely conflicting data. For example, significant toxicity was reported for solution of $30 \mathrm{nM}$ of $\sim 30 \mathrm{~nm}$ AuNPs (Patra et al., 2007), whereas Uboldi et al. (2009) reported only mild toxicity of $30 \mathrm{~nm}$ AuNPs at concentrations of $700 \mu$ M. Minimal toxicity was observed in

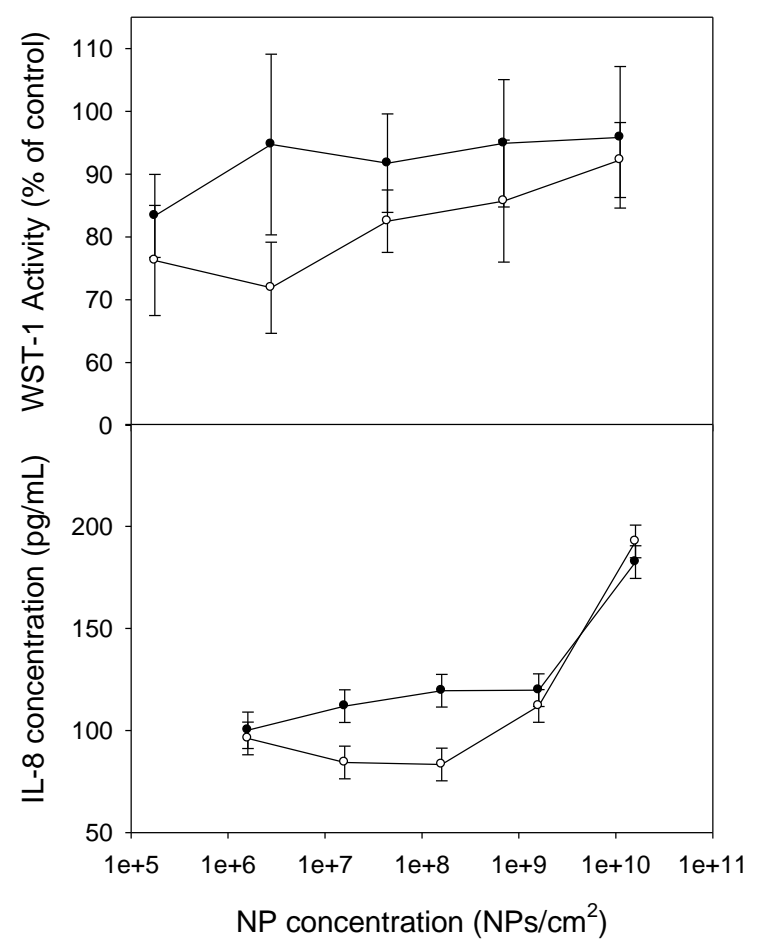

Figure 4: WST-1 activity (top) and IL-8 concentration (bottom) in A549 cells exposed to a range of concentrations of 20 nm NPs (-•-), or $60 \mathrm{~nm}$ NPs (-o-). Data for AuNPs and AgNPs were combined based on statistical analyses. Error bars = standard error of the mean. 
A549 cells exposed to $13 \mathrm{~nm}$ AuNPs at concentrations up to $100 \mu \mathrm{M}$ (Zhao et al., 2011). Here, we observed no significant toxicity associated with 20 and $60 \mathrm{~nm}$ AuNPs even at the highest exposure level of $4.8 \times 10^{10} \mathrm{NPs} / \mathrm{cm}^{2}$, which was equal to $\sim 30$ and $\sim 800 \mathrm{nM}$ concentrations of 20 and $60 \mathrm{~nm}$ AuNPs (based on the mass of gold per liter), respectively. Literature reports with respect to AgNP-induced toxicity in A549 cells are also quite conflicting. Little apoptosis, necrosis, and toxicity have been reported for $6-20 \mathrm{~nm}$, and 150 $\mathrm{nm}$ AgNPs up to $200 \mu \mathrm{g} / \mathrm{mL}$ (Park et al., 2007; AshaRani et al., 2009). In contrast, significant toxicity in A549 cells have been reported for $70 \mathrm{~nm}$ and $80 \mathrm{~nm}$ AgNPs at concentrations of 5 and $15 \mu \mathrm{g} / \mathrm{mL}$, respectively (Sur et al., 2010; Foldbjerg et al., 2011). The toxicity of AgNPs has also been demonstrated to be dependent on the NP size (Carlson et al., 2008; Liu et al., 2010) and surface ligand (Sur et al., 2010). Similar size and shape dependency have been reported with respect to the antibacterial properties of AgNPs (Panacek et al., 2006; Pal et al., 2007). No toxicity due to AgNP exposure was observed in the present study up to levels of $4.8 \times 10^{10} \mathrm{NPs} / \mathrm{cm}^{2}$, concentrations of 3.5 and $95 \mu \mathrm{g} / \mathrm{mL}$ for 20 and $60 \mathrm{~nm}$ AgNPs. Overall, our data suggest occupational exposure levels of AuNPs and AgNPs present a relatively low level risk with respect to cytotoxicity.

Differences in IL-8 secretion was observed based on a significant two-way interaction between NP size and concentration ( $\mathrm{P}=0.03$; Figure 4, bottom). IL-8 levels following exposure to all concentrations of $20 \mathrm{~nm}$ AgNPs and AuNPs differed significantly as compared to the negative control. In contrast, IL-8 levels based on $60 \mathrm{~nm}$ AuNP and AgNP exposure did not differ significantly until an exposure level of greater than $4.8 \times 10^{9}$ $\mathrm{NPs} / \mathrm{cm}^{2}$. These data suggest that NP size plays a significant role with respect to inducing IL8 response in A549 cells. This size-dependent response may result from differential uptake of the NPs by A549 cells. Differences in cellular uptake of engineered nanomaterials based on size have been reported for AgNPs (Liu et al., 2010), AuNPs (Jiang et al., 2008), and singlewalled carbon nanotubes (Jin et al., 2009). Thus increased uptake of smaller (i.e., $20 \mathrm{~nm}$ ) AuNPs and AgNPs may explain the more sensitive IL-8 response observed in our experiments. Further investigation of cellular uptake of 20 and $60 \mathrm{~nm}$ AuNPs and AgNPs, however, is necessary to directly correlate uptake with changes in IL-8 secretion. 


\subsection{Conclusions}

The toxicity and cellular response to AuNPs and AgNPs have been reported for high NP concentrations, but not at occupationally relevant exposure levels and not with NPs precoated with a proteinaceous layer in order to mimic NPs encounter with the surface fluid of the airways upon inhalation. Our present study demonstrates minimal toxicity (WST-1), cytokine response (IL-6), and oxidative stress (HO-1) in A549 alveolar epithelial cells following exposure to AuNPs and AgNPs at levels expected from occupational exposure. Significant increases in the secretion of IL-8, however, were observed for cells exposed to occupational levels of $20 \mathrm{~nm}$, but not $60 \mathrm{~nm}$, AgNPs and AuNPs. Further investigation suggests that the IL- 8 response of A549 cells is dose- and size-dependent, in which $20 \mathrm{~nm}$ NPs elicit a response at a much lower ( 1000-fold lower) concentration as compared to 60 nm NPs. Overall, our data suggest that risks associated with engineered NPs is dependent on their physical properties (chiefly, size) and the concentration of exposure. Moreover, the

effects of NP exposure at occupational exposure levels may be considerably different from those reported in the literature for much higher NP concentrations.

\subsection{References}

AshaRani, P. V., Mun, G. L. K., Hande, M. P., and Valiyaveettil, S. (2009). Cytotoxicity and Genotoxicity of Silver Nanoparticles in Human Cells. ACS Nano 3, 279-290.

Baughman, R. H., Zakhidov, A. A., and de Heer, W. A. (2002). Carbon nanotubes - the route toward applications. Science 297, 787-792.

Brandenberger, C., Rothen-Rutishauser, B., Muhlfeld, C., Schmid, O., Ferron, G. A., Maier, K. L., Gehr, P., and Lenz, A. G. (2010). Effects and uptake of gold nanoparticles deposited at the air-liquid interface of a human epithelial airway model. Toxicol Appl Pharm 242, 56-65.

Carlson, C., Hussain, S. M., Schrand, A. M., Braydich-Stolle, L. K., Hess, K. L., Jones, R. L., and Schlager, J. J. (2008). Unique Cellular Interaction of Silver Nanoparticles: SizeDependent Generation of Reactive Oxygen Species. J. Phys. Chem. B 112, 13608-13619.

Dallas, P., Sharma, V. K., and Zboril, R. (2011). Silver polymeric nanocomposites as advanced antimicrobial agents: Classification, synthetic paths, applications, and perspectives. Adv Colloid Interfac 166, 119-135. 
Foldbjerg, R., Dang, D. A., and Autrup, H. (2011). Cytotoxicity and genotoxicity of silver nanoparticles in the human lung cancer cell line, A549. Arch Toxicol 85, 743-750.

Jiang, W., Kim, B. Y. S., Rutka, J. T., and Chan, W. C. W. (2008). Nanoparticle-mediated cellular response is size-dependent. Nat. Nanotechnol. 3, 145-150.

Jin, H., Heller, D. A., Sharma, R., and Strano, M. S. (2009). Size-Dependent Cellular Uptake and Expulsion of Single-Walled Carbon Nanotubes: Single Particle Tracking and a Generic Uptake Model for Nanoparticles. Acs Nano 3, 149-158.

Kleinsasser, N., Hackenberg, S., Scherzed, A., Kessler, M., Hummel, S., Technau, A., Froelich, K., Ginzkey, C., Koehler, C., and Hagen, R. (2011). Silver nanoparticles: Evaluation of DNA damage, toxicity and functional impairment in human mesenchymal stem cells. Toxicol Lett 201, 27-33.

Koller, M., Mahl, D., Greulich, C., Meyer-Zaika, W., and Epple, M. (2010). Gold nanoparticles: dispersibility in biological media and cell-biological effect. $J$ Mater Chem 20, 6176-6181.

Lewinski, N., Colvin, V., and Drezek, R. (2008). Cytotoxicity of nanoparticles. Small 4, 2649.

Liu, W., Wu, Y. A., Wang, C., Li, H. C., Wang, T., Liao, C. Y., Cui, L., Zhou, Q. F., Yan, B., and Jiang, G. B. (2010). Impact of silver nanoparticles on human cells: Effect of particle size. Nanotoxicology 4, 319-330.

Maynard, A. D., Aitken, R. J., Butz, T., Colvin, V., Donaldson, K., Oberdorster, G., Philbert, M. A., Ryan, J., Seaton, A., Stone, V., Tinkle, S. S., Tran, L., Walker, N. J., and Warheit, D. B. (2006). Safe handling of nanotechnology. Nature 444, 267-269.

Mohamed, B. M., Verma, N. K., Prina-Mello, A., Williams, Y., Davies, A. M., Bakos, G., Tormey, L., Edwards, C., Hanrahan, J., Salvati, A., Lynch, I., Dawson, K., Kelleher, D., and Volkov, Y. (2011). Activation of stress-related signalling pathway in human cells upon $\mathrm{SiO}(2)$ nanoparticles exposure as an early indicator of cytotoxicity. $J$ Nanobiotechnol 9.

Moller, W., Felten, K., Sommerer, K., Scheuch, G., Meyer, G., Meyer, P., Haussinger, K., and Kreyling, W. G. (2008). Deposition, retention, and translocation of ultrafine particles from the central airways and lung periphery. Am J Resp Crit Care 177, 426-432. 
Monteiro-Riviere, N. A., Samberg, M. E., and Oldenburg, S. J. (2010). Evaluation of Silver Nanoparticle Toxicity in Skin in Vivo and Keratinocytes in Vitro. Environ Health Persp 118, 407-413.

Nabikhan, A., Kandasamy, K., Raj, A., and Alikunhi, N. M. (2010). Synthesis of antimicrobial silver nanoparticles by callus and leaf extracts from saltmarsh plant, Sesuvium portulacastrum L. Colloid Surface B 79, 488-493.

Nel, A. E., Xia, T., Kovochich, M., Brant, J., Hotze, M., Sempf, J., Oberley, T., Sioutas, C., Yeh, J. I., and Wiesner, M. R. (2006). Comparison of the abilities of ambient and manufactured nanoparticles to induce cellular toxicity according to an oxidative stress paradigm. Nano Lett. 6, 1794-1807.

Oberdorster, G., Oberdorster, E., and Oberdorster, J. (2005). Nanotoxicology: An emerging discipline evolving from studies of ultrafine particles. Environ. Health Perspect. 113, 823-839.

Pal, S., Tak, Y. K., and Song, J. M. (2007). Does the antibacterial activity of silver nanoparticles depend on the shape of the nanoparticle? A study of the gram-negative bacterium Escherichia coli. Appl Environ Microb 73, 1712-1720.

Panacek, A., Kvitek, L., Prucek, R., Kolar, M., Vecerova, R., Pizurova, N., Sharma, V. K., Nevecna, T., and Zboril, R. (2006). Silver colloid nanoparticles: Synthesis, characterization, and their antibacterial activity. J Phys Chem B 110, 16248-16253.

Park, S., Lee, Y. K., Jung, M., Kim, K. H., Chung, N., Ahn, E. K., Lim, Y., and Lee, K. H. (2007). Cellular toxicity of various inhalable metal nanoparticles on human alveolar epithelial cells. Inhal Toxicol 19, 59-65.

Patra, H. K., Banerjee, S., Chaudhuri, U., Lahiri, P., and Dasgupta, A. K. (2007). Cell selective response to gold nanoparticles. Nanomed-Nanotechnol 3, 111-119.

Phalen, R. F., Oldham, M. J., and Nel, A. E. (2006). Tracheobronchial particle dose considerations for in vitro toxicology studies. Toxicol. Sci. 92, 126-132.

Ryman-Rasmussen, J. P., Riviere, J. E., and Monteiro-Riviere, N. A. (2007). Surface coatings determine cytotoxicity and irritation potential of quantum dot nanoparticles in epidermal keratinocytes. J. Invest. Dermatol. 127, 143-153. 
Shin, D. C., Jang, J. Y., Yang, J. Y., Kim, S. H., Choi, I. H., Lim, Y. W., Kim, C. S., and Lee, G. T. (2008). Cytotoxicity of Nano-materials on Human Bronchial Epithelial Cell. NSTI Nanotech 2008, Vol 2, Technical Proceedings, 142-145.

Smart, S. K., Cassady, A. I., Lu, G. Q., and Martin, D. J. (2006). The biocompatibility of carbon nanotubes. Carbon 44, 1034-1047.

Sperling, R. A., Rivera Gil, P., Zhang, F., Zanella, M., and Parak, W. J. (2008). Biological applications of gold nanoparticles. Chemical Society Reviews 37, 1896-1908.

Stone, V., and Donaldson, K. (2006). Nanotoxicology - Signs of stress. Nat. Nanotechnol. 1, 23-24.

Sur, I., Cam, D., Kahraman, M., Baysal, A., and Culha, M. (2010). Interaction of multifunctional silver nanoparticles with living cells. Nanotechnology 21.

Uboldi, C., Bonacchi, D., Lorenzi, G., Hermanns, M. I., Pohl, C., Baldi, G., Unger, R. E., and Kirkpatrick, C. J. (2009). Gold nanoparticles induce cytotoxicity in the alveolar type-II cell lines A549 and NCIH441. Part Fibre Toxicol 6.

Yen, H. J., Hsu, S. H., and Tsai, C. L. (2009). Cytotoxicity and Immunological Response of Gold and Silver Nanoparticles of Different Sizes. Small 5, 1553-1561.

Zhao, Y. X., Gu, X. H., Ma, H. Z., He, X. G., Liu, M., and Ding, Y. (2011). Association of Glutathione Level and Cytotoxicity of Gold Nanoparticles in Lung Cancer Cells. J Phys Chem C 115, 12797-12802. 


\section{High-throughput Screening of Transglutaminase Activity using Plasmonic Fluorescent Nanocomposites}

\subsection{Chapter Summary}

Plasmonic fluorescent nanocomposites are difficult to prepare due to the strong quenching of fluorophores in the vicinity of plasmonic noble metal nanoparticles (NPs) such as gold or silver (AuNPs or AgNPs). We recently reported the characterization of plasmonic fluorescent nanocomposites from the aggregation of two cyanine dyes on a wide range of AuNPs sizes, including 10nm AuNPs conjugated to streptavidin (10nm AuNPs-SA). We now describe for the first time a high-throughput screening assay for transglutaminase based on plasmonic fluorescent nanocomposites. We first crosslinked biotinylated pentylamine to casein immobilized in 384-well microplates. We then bound 10nm AuNPs-SA to biotin and we elicited absorption and fluorescence signals following the self-assembly of cyanines upon the AuNPs. Our assay enables both absorption and fluorescence signaling within a single assay format in the green-to-red regions of the electromagnetic spectrum which minimizes the blue-green autofluorescence interferences of biological samples. The cyanine dyes may be added sequentially to elicit first the green and then the red spectral responses from the same reactions, in the same microwells eliminating the need for separate sets of reactions for probing with the two types of dyes. The multi-wavelengths interrogation offers fast results (near-instantaneous "mix and measure") and high sensitivity (limit of detection, 5ng TG, 63 fmol). Plasmonic fluorescent nanocomposites offer new ways of interrogating chem-bio molecules for improved sensitivity and specificity.

\subsection{Introduction}

Plasmonic fluorescent nanocomposites are composed of fluorophores located on or in the vicinity of noble metals such as gold and silver nanoparticles (AgNPs and AuNPs). ${ }^{[1]}$ Plasmonic fluorescent nanocomposites are difficult to prepare due to the strong fluorescence quenching effects of the noble metal NPs. Successful preparation of plasmonic fluorescent nanocomposites often involves the chemical synthesis of core-shell configuration in order to protect the fluorophore from quenching by AgNPs or AuNPs, or by optimizing the size of the NPs or by distancing the NPs from fluorophores. ${ }^{[2-4]}$ We were recently successful in 
preparing noncovalent ensembles of plasmonic fluorescent nanocomposites consequent to the supramolecular self-assembly of two different cyanine dyes upon a wide range of AuNPs sizes $(2 \mathrm{~nm}$ to $40 \mathrm{~nm})$, including $10 \mathrm{~nm}$ AuNPs that were covalently conjugated to streptavidin (10nm AuNPs-SA). These nanocomposites were intensely fluorescent in the green-to-red regions of the electromagnetic (EM) spectrum. ${ }^{[5]}$ Plasmonic fluorescent nanocomposites are an exciting and emerging area of research which will benefit from the demonstration of their practical applications.

Transglutaminases (TGs) are ubiquitous enzymes present in plants, animals and microorganisms where they play diverse roles including apoptosis, wound healing, extracellular matrix development, hemostasis and thrombosis. ${ }^{[6,7]}$ Among the several different types of reactions catalyzed by TG, a frequently cited one is the covalent crosslinking of primary amines to the $\gamma$-carboxamide group of protein- or peptide-bound glutamine residues resulting in the formation of an isopeptide bond. ${ }^{[6,7]}$ TGs have been identified as targets for pharmacological inhibition and compound libraries were screened for inhibitors of enzymatic activity. ${ }^{[8-10]}$ We utilized TG for a practical application of plasmonic fluorescent nanocomposites by developing a new high throughput screening (HTS) assay for this enzyme which may be a relevant marker for cell toxicity.

Briefly, dimethylcasein (glutamine substrate) was noncovalently adsorbed to 384-well microplate followed by TG-catalyzed covalent crosslinking of 5 , biotinamidopentylmine (primary amine substrate) to the protein. The biotin was then bound to 10nm AuNPs-SA via strong $\left(\mathrm{Ka} \sim 10^{13} \mathrm{M}^{-1}\right)$ streptavidin-biotin interactions. ${ }^{[11]}$ Finally, supramolecular selfassembly of cyanine dyes upon the AuNPs resulted in the orthogonal absorption and fluorescence signals. The signaling was most likely due to the formation of the so-called cyanine "J-aggregates". ${ }^{[12]}$ It was useful that this HTS assay invoked signaling in the red-tonear-infrared (NIR) regions of the EM spectrum in order to minimize blue-green autofluorescence and light scattering by biological samples. Such autofluorescence and scattering degrade assay sensitivity and specificity. The HTS assay using plasmonic fluorescent nanocomposites enabled fast ("mix-and-measure") and sensitive (5ng, 60 fmol) 
detection of TG. This is the first example of our efforts using plasmonic fluorescent nanocomposites for the HTS of enzyme activity.

\subsection{Materials and Methods}

\subsubsection{Materials}

Purified guinea pig liver TG, N,N'-dimethylcasein (DMC), dithiothreitol (DTT), calcium chloride $\left(\mathrm{CaCl}_{2}\right)$, ethylenediamine tetraacetic acid (EDTA), methanol and 10nm AuNPs (6.1 x $10^{12}$ particles $/ \mathrm{mL}$ ) covalently conjugated to streptavidin (SA) (10nm AuNPs-SA) were purchased from Sigma Aldrich, St. Louis, MO. Cyanines 1 (5,6-Dichloro-2-[3-(5,6-dichloro1,3-diethyl-1,3-dihydro-benzoimidazol-2-ylidene)-propenyl]-1,3-diethyl-3H-benzoimidazol1-ium) and 2 (1-Methyl-2-[3-(1-methyl-1H-naphtho[1,2-d]thiazol-2-ylidene)-2-phenylpropenyl]-naphtho[1,2-d]thiazol-1-ium) (Fig. 1) were obtained as gifts. ${ }^{[5]}$ The amine substrate, 5'-biotinamidopentylamine (BP), bicinchonnic acid (BCA) protein assay kit and plate sealing tape were purchased from Pierce Chemical Company (Rockford, IL). SuperBlock T-20 blocking solution and 384-well density microplates of the "high protein binding" type polystyrene clear plates were purchased from Thermo Scientific, Hudson, NH. Polystyrene 384-well white plates were from Optiplate, Perkin Elmer Life Sicences, Boston, MA. Reaction buffer of 50mM Tris-Cl, $\mathrm{pH} 7.5$ was used for dissolving all reagents used in the assays as well as the medium in which TG reactions were carried out.

\subsubsection{High-Throughput Screening (HTS) of TG Catalysis}

High-throughput screening (HTS) of TG activity was carried out essentially as described

previously. ${ }^{[13]}$ Briefly, $50 \mu \mathrm{L}$ of DMC $\left(M r, 25,000,{ }^{[14]}\right)$ solution was used to coat microplate wells overnight at $4^{\circ} \mathrm{C}$. The DMC solution was then discarded and the residual proteinbinding sites of the wells were blocked using $\sim 120 \mu \mathrm{L} /$ well of SuperBlock for 60 minutes at room temperature $\left(\sim 25^{\circ} \mathrm{C}\right)$. Then the SuperBlock solution was discarded and the wells washed thrice using $\sim 120 \mu \mathrm{L} /$ well of SuperBlock and thrice using similar volumes of reaction buffer. A cocktail of TG reaction reagents was prepared in reaction buffer such that the concentration in $50 \mu \mathrm{L} /$ well of final volume was composed of $10 \mathrm{mM} \mathrm{CaCl} 2$ and $5 \mathrm{mM}$ DTT along with the indicated concentrations of the amine substrate (BP) and TG. Control reactions omitted TG or were with EDTA replacing $\mathrm{Ca}^{2+}$. Except during initial experiments 
comparing the assay sensitivity in 384-well clear and white plates and the final absorption assays in 384-well clear plates, all other experiments were carried out using 384-well white plates. The TG reaction volumes were discarded and the wells were washed as described above. Then, 50 $\mu \mathrm{L} /$ well of 10nm AuNPs-SA diluted in SuperBlock T-20 (defined as gold nanoparticles $/ \mathrm{mL}$ ) was added and incubated in order to allow the binding of SA to the biotin in the BP. Temperature $\left(25^{\circ} \mathrm{C}, 37^{\circ} \mathrm{C}\right.$ ) or binding time (30 to 60 minutes) did not appear to influence the binding of $10 \mathrm{~nm}$ AuNPs-SA to biotin as determined by the eventual signal strength. Then, the 10nm AuNPs-SA solution was disposed as nanomaterial waste. The reaction wells were washed thrice with SuperBlock T-20 and thrice with $\mathrm{H}_{2} \mathrm{O}(\sim 120 \mu \mathrm{L} /$ well). Finally, cyanine 1 or 2 dissolved in methanol-water $(20: 80, v / v)$ was added to the reaction

wells. Red-shifted J-band absorption or fluorescence ${ }^{[5,12]}$ was detected as the spectroscopic responses of the plasmonic fluorescent nanocomposites, signaling TG catalysis. In the case of sequential dye additions, either cyanine $\mathbf{1}$ or $\mathbf{2}$ was first added to the reaction wells, fluorescence measurements were taken and the solutions were emptied from the wells. The wells were then thoroughly washed using methanol- $\mathrm{H}_{2} \mathrm{O}(20: 80)$ mixture and then with water to remove as much of the noncovalent nanocomposites as possible, and the wells patted dry on filter paper pads, before probing with the other cyanine dye. Additional experimental details are mentioned in the legends to the appropriate figures. Changes to absorption (absorption units, $\mathrm{AU}$ ) and fluorescence intensities (relative fluorescence units, RFU) as a consequence of $\mathrm{TG}$ catalysis were monitored. In some experiments, changes to signal/background (S/B) were used as an index of TG activity. Data analyses were carried out as described previously. ${ }^{[5]}$

\subsubsection{Plasmonic Fluorescent Nanocomposites}

Absorption assays were conducted in clear plates to facilitate absorption spectral scans and fluorescence measurements were carried out mostly using white wells for higher signal strength. Fluorescence assays were conducted in clear polystyrene plates for comparing assay performance in clear and white plates or to facilitate the same reactions to be interrogated using both absorption and fluorescence techniques. Plasmonic fluorescent nanocomposites were formed by adding the cyanine (1 or 2 ) to the wells and agitating briefly (30 to $45 \mathrm{sec}$ ) using the "automix" function of the microplate reader for achieving uniform, thorough 
mixing in order to facilitate spontaneous self-assembly of cynanines upon the AuNPs scaffolds. ${ }^{[5]}$ Absorption reactions using cyanine 1 were scanned between 540 to $630 \mathrm{~nm}$ in $2 \mathrm{~nm}$ intervals and wells containing 2 nanocomposites were scanned between 640 to $720 \mathrm{~nm}$ in $2 \mathrm{~nm}$ intervals as described previously. ${ }^{[5]}$ Fluorescence was measured using the excitation / emission wavelengths optimized previously for cyanines $\mathbf{1}$ and $\mathbf{2}$ plasmonic fluorescent nanocomposites. ${ }^{[5]}$ Thus, 1 nanocomposites were excited at $500 \mathrm{~nm}$ and the emission was monitored at 592nm and 2 plasmonic nanocomposites were measured by exciting the samples at $630 \mathrm{~nm}$ and monitoring the emission at $700 \mathrm{~nm} .^{[5]}$ Absorption and fluorescence measurements were taken using a Molecular Devices M2 microwell plate reader (Sunnyvale, CA).

\subsection{Results and Discussion}

\subsubsection{Assay format}

A schematic of our HTS assay format for TG activity using plasmonic fluorescent nanocomposites is shown in Fig. 1 along with the structures of cyanine dyes $\mathbf{1}$ and $\mathbf{2}$ for spontaneously self-assembling upon 10nm AuNPs-SA which resulted in the absorption and fluorescence signals. Briefly, the assay principle involves covalent crosslinking of biotinylated amine peptide substrate to casein protein immobilized in microwell plates. The biotin in the peptide subsequently binds to $10 \mathrm{~nm}$ AuNPs-SA thereby facilitating the selfassembly of cyanine $\mathbf{1}$ and/or $\mathbf{2}$, resulting in the characteristic, red-shifted J-band absorption and fluorescence signals ${ }^{[12]}$ that were indicative of TG catalysis (Fig. 1). Increasing TG catalysis (as a consequence of increasing enzyme concentration or reaction time, for example) will result in increasing concentrations of 10nm AuNPs-SA binding to BP which in turn leads to increasing concentrations of cyanine aggregates being formed with their characteristic absorption and fluorescence properties. In order for the assays to be HTScompatible, all reactions were carried out using 384-well (clear or white) microwell plates. ${ }^{[15]}$ Additional details are provided in the Materials and Methods section of the paper and overall assay conditions were derived from an absorption-based microwell plate TG assay described previously. ${ }^{[13]}$ 
<smiles></smiles>

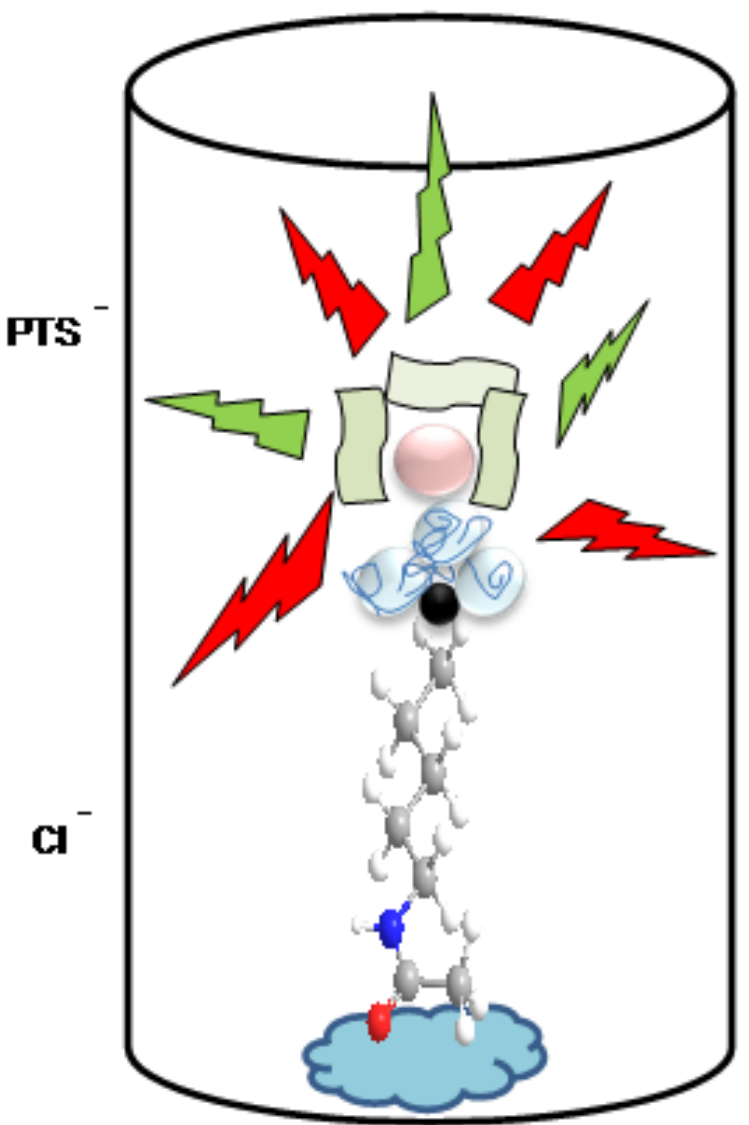

Fig. (1). Schematic of plasmonic fluorescent nanocomposites for HTS of TG activity and structures of cyanines used. The left side shows the chemical structures of cyanine 1 (top) and 2 (bottom) used in this work to create the nanocomposites. The right side shows a schematic of the HTS format. Dimethylcasein (blue cloud) is immobilized to the bottom of the microplate well (cylindrical outline) and is crosslinked to BP (pentylamine shown in balland-stick configuration) via TG catalysis. The black circle is biotin at the end of the BP chain which binds to $10 \mathrm{~nm}$ AuNPs-SA. The streptavidin is shown by the squiggly lines encased in aqua colored circles that are topped by a 10nm AuNP reddish-purple sphere. The cyanine $\mathbf{1}$ and/or 2 aggregates are atop the AuNP (wavy rectangles). The green and red thunderbolts represent the green and red absorption and emission signals from the plasmonic nanocomposites.

\subsubsection{Theory of plasmonic fluorescent nanocomposites}

Cyanine dyes self-assemble upon a variety of chemical and biological scaffolds forming fluorescent J-aggregates or non-fluorescent $\mathrm{H}$-aggregates. Cyanine aggregates display narrow absorption (J-band) that is red-shifted relative to monomer absorption, bright fluorescence, and electrochemical activity. ${ }^{[12]}$ Since, cyanine monomers are non-fluorescent or weakly 
fluorescent, cyanine aggregates display high S/B and are useful for developing novel HTS assays. In this context electron-rich noble metal (gold, silver) nanoparticles (NPs) are interesting because of their ability to scaffold cyanines ${ }^{[5}$ and references therein] and their intense extinction (absorption + scattering), where the incident visible light frequency is resonant with conduction band free electron oscillations, a phenomenon known as localized surface plasmon resonance (LSPR). ${ }^{[1]}$ Overlap of LSPR with absorption/excitation spectra of the cyanine aggregates contributed to fluorescence instead of nanometal-induced quenching. ${ }^{[5}$ and references therein]

In order to demonstrate proof-of-concept, we assembled increasing concentrations of cyanines 1 and 2 upon two different concentrations of the scaffold 10nm AuNPs-SA, and studied the absorption and fluorescence properties of the nanocomposites and compared these with the absorption and fluorescence properties of the respective monomers. This was to mimic TG catalysis but in the absence of the enzyme. Cyanine $\mathbf{1}$ produced a concentrationdependent increase in red-shifted absorption with peak around 590nm following aggregation upon two different concentrations of the 10nm AuNPs-SA scaffold (Fig. 2A, panels I and II). This was accompanied by a parallel decrease in 1 monomer peak absorption around 510nm at both concentrations of the scaffold (10nm AuNPs-SA). Expectedly, the increase in redshifted absorption was higher with $2.4 \times 10^{10} / \mathrm{mL} 10 \mathrm{~nm}$ AuNPs-SA compared to $2.4 \mathrm{x}$ $10 \% / \mathrm{mL}$ due to the availability of larger numbers of gold nanoparticles to support the aggregation of cyanine (Fig. 2A; compare 590nm absorption intensities of panels I and II). Saturation of absorption intensities was between $25 \mu \mathrm{M}$ and $50 \mu \mathrm{M}$ with 1 . Nearly identical dose-response absorption profiles were also obtained with $\mathbf{2}$, except that the absorption changes of the 2 monomer was monitored around 550nm and 590nm, whereas the 2 nanocomposites absorption changes were around 690nm. Saturation of 2 aggregates absorption was between $5 \mu \mathrm{M}$ and $25 \mu \mathrm{M} 2$ with the higher concentration of scaffold (Fig. 2A, panels III and IV). 

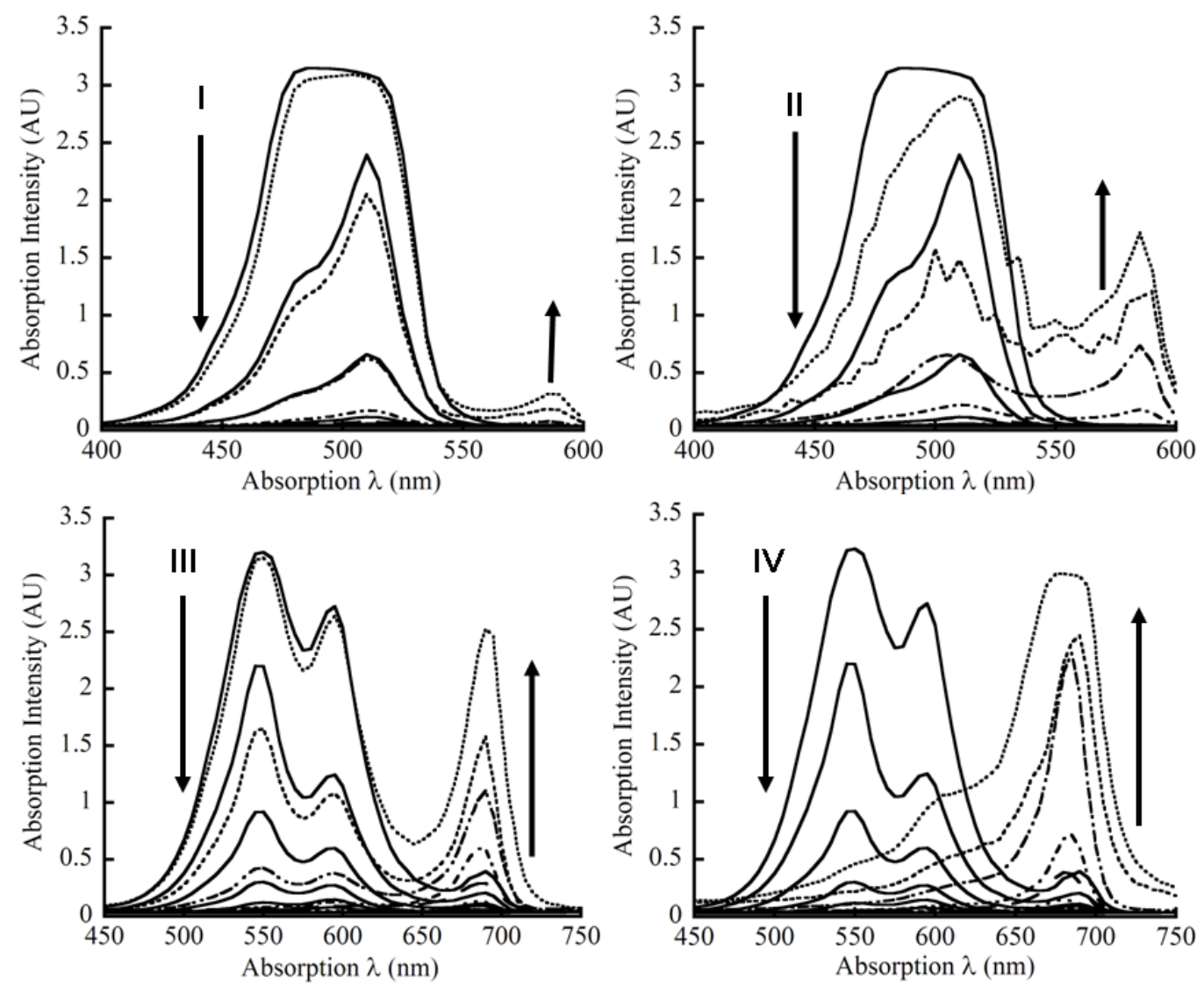

Fig. (2A). Absorption scans of 1 and 2 plasmonic nanocomposites independent of TG catalysis. These results show proof-of-concept of using red-shifted absorption changes consequent to cyanine aggregation on 10nm AuNPs-SA scaffolds in order to monitor TG catalysis as explained in the text. The concentrations of cyanine $\mathbf{1}$ (panels, I and II) and

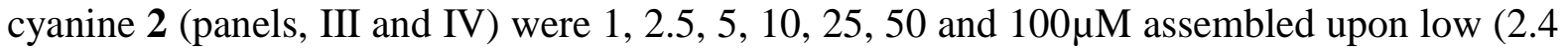
x $10^{9} \mathrm{NPs} / \mathrm{mL}$; panels I and III) and high $\left(2.4 \times 10^{10} \mathrm{NPs} / \mathrm{mL}\right.$; panels II and IV) concentrations of 10nm AuNPs-SA. The downward and upward pointing arrows represent decreasing and increasing absorption intensities of the monomers and the aggregates, respectively, as a result of adding increasing concentrations of the dye to the scaffolds. All reactions were carried out in a total volume of $50 \mu \mathrm{L}$ in methanol/water mixture $(20 / 80, \mathrm{v} / \mathrm{v})$ using 384-well clear plates as described previously. ${ }^{[5]}$

We next examined the fluorescence behavior of $\mathbf{1}$ and $\mathbf{2}$ nanocomposites as a function of dye (1 and 2) and scaffold (10nm AuNPs-SA) concentrations in a manner analogous to the above absorption studies. Fluorescence intensities increased with increasing concentrations of $\mathbf{1}$ or $\mathbf{2}$ as well as with increasing concentration of 10nm AuNPs-SA (Fig. 2B, panels I through IV). Depending on the concentration of $\mathbf{1}$ and $\mathbf{2}$ monomers, only weak fluorescence was observed 
in the absence of the scaffold. The fluorescence emission of the monomers was also indistinguishable from background fluorescence of the reaction vehicle (methanol/ $\mathrm{H}_{2} \mathrm{O}$, 20/80, v/v) or the fluorescence of the scaffold (10nm AuNPs-SA) in the absence of the dyes. Furthermore, emission was approximately 5-fold stronger with 1 nanocomposites relative to 2 nanocomposites (Fig. 2B, compare panels I and III; II and IV). These data established baseline conditions for examining TG catalysis using plasmonic fluorescent nanocomposites.
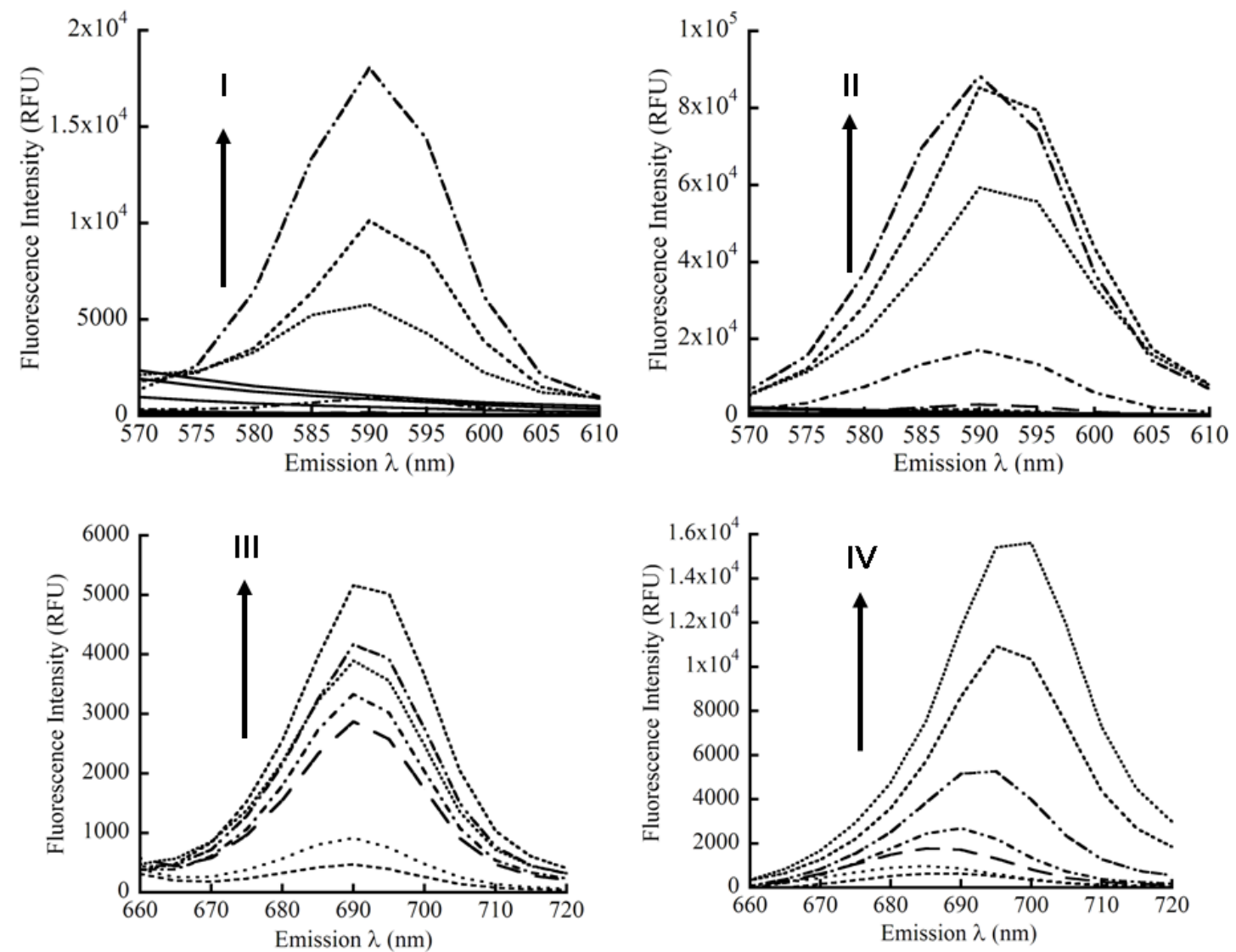

Fig. (2B). Fluorescence emission scans of 1 and 2 plasmonic nanocomposites independent of TG catalysis. These results show proof-of-concept of using fluorescence changes consequent to cyanine aggregation on $10 \mathrm{~nm}$ AuNPs-SA scaffolds in order to monitor TG catalysis as explained in the text. The concentrations of cyanine $\mathbf{1}$ (panels, I and II) and cyanine $\mathbf{2}$ (panels, III and IV) were 1, 2.5, 5, 10, 25, 50 and $100 \mu \mathrm{M}$ assembled upon low $\left(2.4 \times 10^{9}\right.$ $\mathrm{NPs} / \mathrm{mL}$; panels I and III) and high $\left(2.4 \times 10^{10} \mathrm{NPs} / \mathrm{mL}\right.$; panels II and IV) concentrations of $10 \mathrm{~nm}$ AuNPs-SA. The upward pointing arrows represent increasing emission intensities of the aggregates as a result of adding increasing concentrations of the dye to the scaffolds. All reactions were carried out in a total volume of $50 \mu \mathrm{L}$ in methanol/water mixture $(20 / 80, \mathrm{v} / \mathrm{v})$ using 384-well white plates as described previously. ${ }^{[5]}$ 
Two additional points deserve mention. 1) We previously showed that the scaffolding by $10 \mathrm{~nm}$ AuNPs-SA was probably due to the gold nanoparticles and not due to streptavidin protein. We could not however, definitively exclude the possibility that streptavidin covalently conjugated to $10 \mathrm{~nm}$ AuNPs might undergo a conformational change to facilitate cyanine aggregation on the protein. ${ }^{[5]}$ More likely, the streptavidin served as a "spacer" layer mitigating the quenching effects of the nanometal and thereby enabling fluorescence emission from the nanocomposites ${ }^{[16-22]}$ since when cyanine J-aggregates were directly adsorbed on AuNPs, the fluorescence was quenched. ${ }^{[19]}$ Regardless of the mechanism of the absorption and fluorescence changes, these data establish the suitability of plamonic fluorescent nanocomposites as signals for TG catalysis in a HTS environment. 2) The NIR (690nm to 700nm) absorption and emission wavelengths of the 2 nanocomposites are useful for screening biological samples because fluorophores with emission $\lambda>650 \mathrm{~nm}$ are uncommon $^{[20,23,24]}$, but desirable because they avoid the so called "water window" of biological specimens. The NIR absorbing/emitting molecules avoid the blue-green regions of the EM spectrum where there is interference from the intrinsic absorption and fluorescence from biological materials and also degrade the S/B. We next moved to documenting the signaling from these nanocomposites as an actual consequence of TG enzymatic catalysis.

\subsubsection{Clear versus white plates}

Using the assay format described above, we first investigated the fluorescence signal intensity from reactions conducted using polystyrene clear plates or white plates with cyanine 1 (Fig. 3). Both the signal intensity and the S/B values were significantly lower when the reactions were carried out in clear plates compared to reactions in white plates, even though the linearity of all four tracings were similar (correlation of coefficient, $r^{2} \geq 0.96$ ). The results indicated that for fluorescence measurements, white plates were better suited. However, if the goal was to combine absorption (vide infra) and fluorescence signal measurements within a single plate format, then clear plates should be used for TG catalysis. There may be several reasons for the lower fluorescence intensity and approximately 4-fold lower S/B values of the clear plate reactions. Even though the clear plate was designated by the manufacturer as "high protein binding" capacity, the extent of DMC immobilization might not be sufficiently high to permit optimal signaling when compared to white plates. More probably however, the 
"high protein binding" capacity of the clear plate in fact allowed the chemisorption of excess DMC to the plate well resulting in a decline in TG activity (vide infra). The clear plate may also result in greater scattering as well as "cross talk" resulting in S/B values becoming lower compared to white plate. The internal reflections from the white well walls are also known to enhance fluorescence emission intensity ${ }^{[25]}$ leading to the approximately 10 -fold higher emission from white plate reactions. Since fluorescence is considered to be the "gold standard" for HTS applications ${ }^{[15]}$, we focused our attention on optimizing the assay parameters using fluorescence emission from white plates using 1 and 2 plasmonic fluorescent nanocomposites. Toward the end of the work, we revert to assay performance using absorption assays.

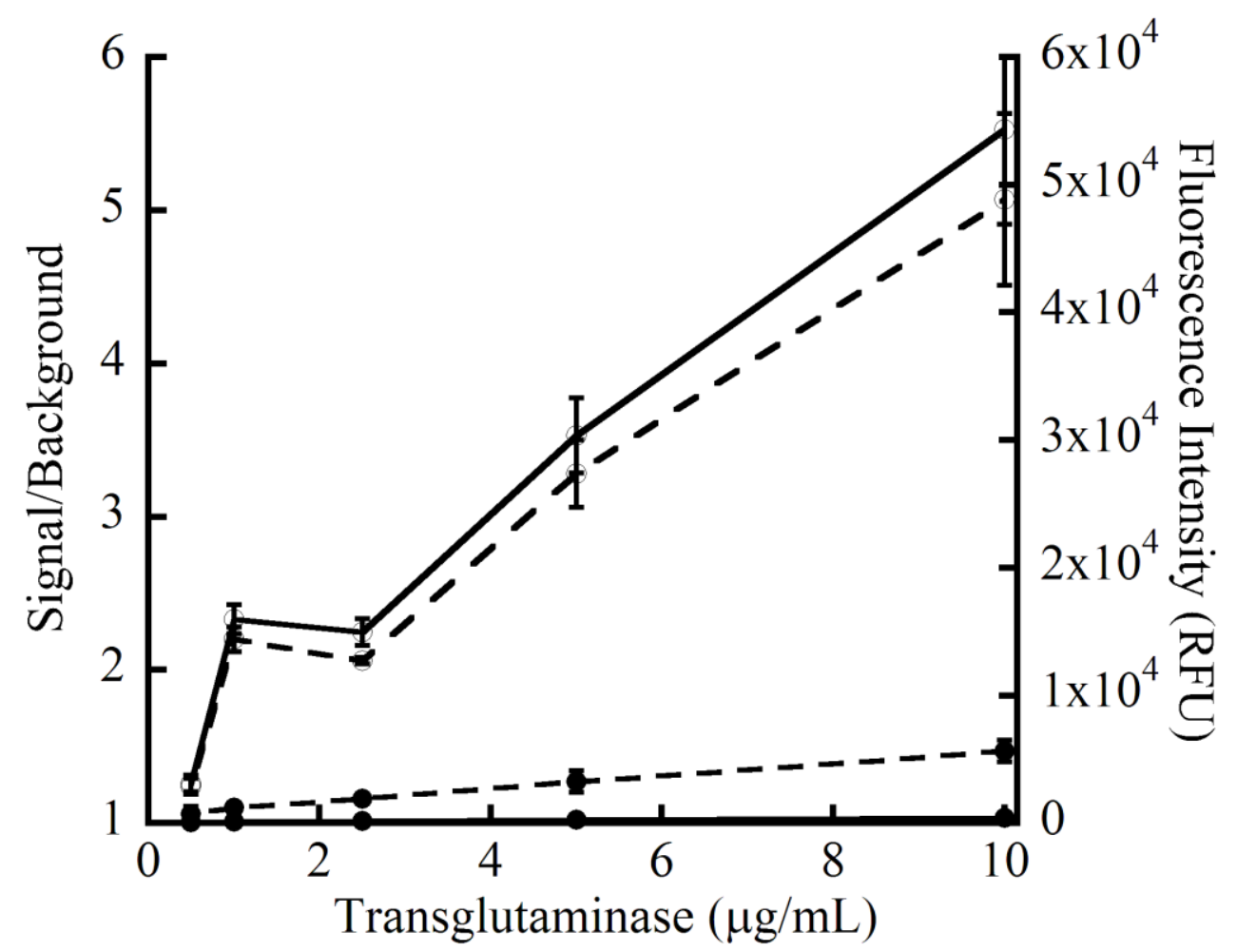

Fig. (3). HTS of TG activity using cyanine 1 plasmonic fluorescent nanocomposite signaling in clear and white microwell plates. TG activity was carried out under identical conditions using clear (closed circles) or white (open circles) microwell plates. Solid tracings represent fluorescence emission intensity as relative fluorescence units (RFU) and broken tracings are $\mathrm{S} / \mathrm{B}$ values. Increasing and indicated concentrations of TG were used to crosslink a $1 \mathrm{mM}$ solution of BP to immobilized DMC $(5 \mathrm{mg} / \mathrm{mL})$ at room temperature $\left(\sim 25^{\circ} \mathrm{C}\right)$ for 30 minutes. The $10 \mathrm{~nm}$ AuNPs-SA concentration was $2.4 \times 10^{11} / \mathrm{mL}$ and the concentration of cyanine 1 was $50 \mu \mathrm{M}$. 


\subsubsection{Optimization of TG reactants}

In the next series of experiments we optimized the concentrations of the various reactants taking part in TG catalysis. The glutamine-donating protein substrate DMC showed a

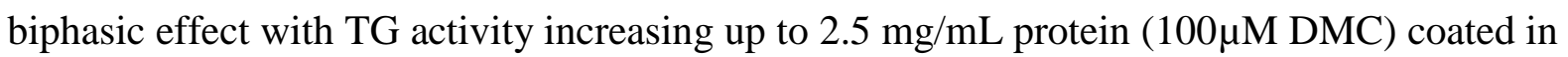
microplate wells and declining thereafter in reactions probed using either cyanine $\mathbf{1}$ or $\mathbf{2}$ (Fig. 4). This is close to the concentration of $5 \mathrm{mg} / \mathrm{mL}$ casein used previously by Kamiya et al. ${ }^{[26]}$ and the $50-100 \mu \mathrm{M}$ DMC used previously. ${ }^{[9,27]}$ The biphasic profile of the glutamine-donating casein substrate (Fig. 4) was similar to the biphasic profile obtained using a synthetic glutamine-peptide substrate to measure TG activity. ${ }^{[28]}$ As noted above, the protein binding capacity of even the white plate might have contributed to lower S/B values at higher concentrations of DMC coating with the plasmonic fluorescent signaling system. Consistent with our previous results using plasmonic fluorescent nanocomposites ${ }^{[5]}$, emission intensity from 1 nanocomposites was higher than the emission intensity from 2 nanocomposites (Fig. 4), a trend that was observed throughout these studies. Since the emission profiles (but not the intensity) were similar with both cyanines, we used $2.5 \mathrm{mg} / \mathrm{mL}$ solution of DMC to coat the microplate wells in all further experiments.

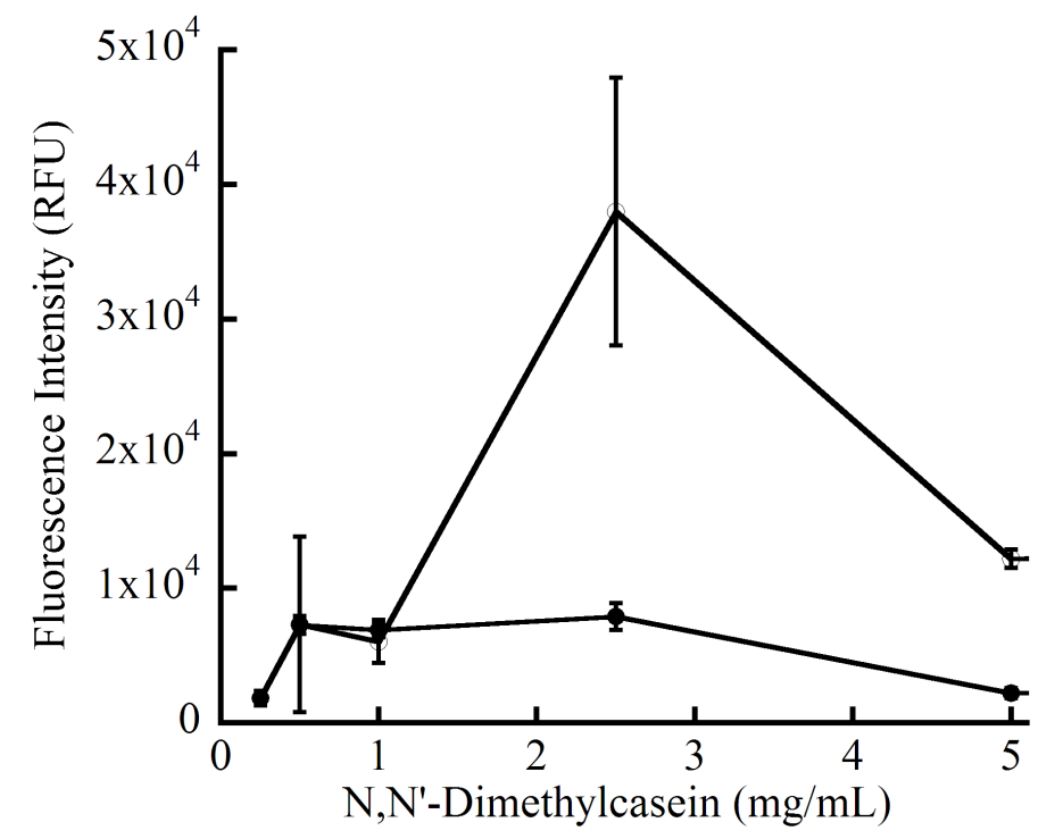

Fig. (4). Optimization of DMC concentration for the measurement of TG activity using plasmonic fluorescent nanocomposites. Increasing and indicated concentrations of DMC 
were coated in 384-well white microplates. TG $(5.7 \mu \mathrm{g} / \mathrm{mL})$ was used to crosslink a $2 \mathrm{mM}$ solution of BP to DMC at $37^{\circ} \mathrm{C}$ for 30 minutes. The concentration of $10 \mathrm{~nm}$ AuNPs-SA was $2.4 \times 10^{11} / \mathrm{mL}$ and the concentration of cyanines $\mathbf{1}$ (open circles) and $\mathbf{2}$ (closed circles) were $25 \mu \mathrm{M}$ and $10 \mu \mathrm{M}$, respectively.

Optimization of the primary amine substrate also revealed similar profiles (though not similar fluorescence emission intensities (as noted with DMC data) regardless of whether the plasmonic fluorescent nanocomposites were formed using cyanine 1 or 2 (Fig. 5). Since the emission intensity was approximately 10-fold lower with 2 plasmonic nanocomposites relative to 1 nanocomposites, we tested the fluorescence signaling using two different concentrations of $\mathrm{TG}$ and obtained similar results. All tracings showed maximal signal strength at approximately $100 \mu \mathrm{M}$ BP. Although not determined in the present work, we previously found the same concentration $(100 \mu \mathrm{M})$ of the BP substrate to represent the $K m$ for guinea pig liver TG and we had previously used a five-fold excess BP concentration $(500 \mu \mathrm{M})$ for routine measurements of TG activity. ${ }^{[13]}$ Based on these comparisons, we used $500 \mu \mathrm{M}$ BP substrate in all subsequent experiments in the present work. Although the present work and earlier results were separated by about two decades, the overall assay parameters were similar. In view of these similarities, we used earlier concentrations of $10 \mathrm{mM} \mathrm{CaCl} 2$ and $5 \mathrm{mM}$ of reduced thiol in the reaction mixtures, since TG activity had been assayed over these concentrations of the cofactors. ${ }^{[9,13,27-30]}$

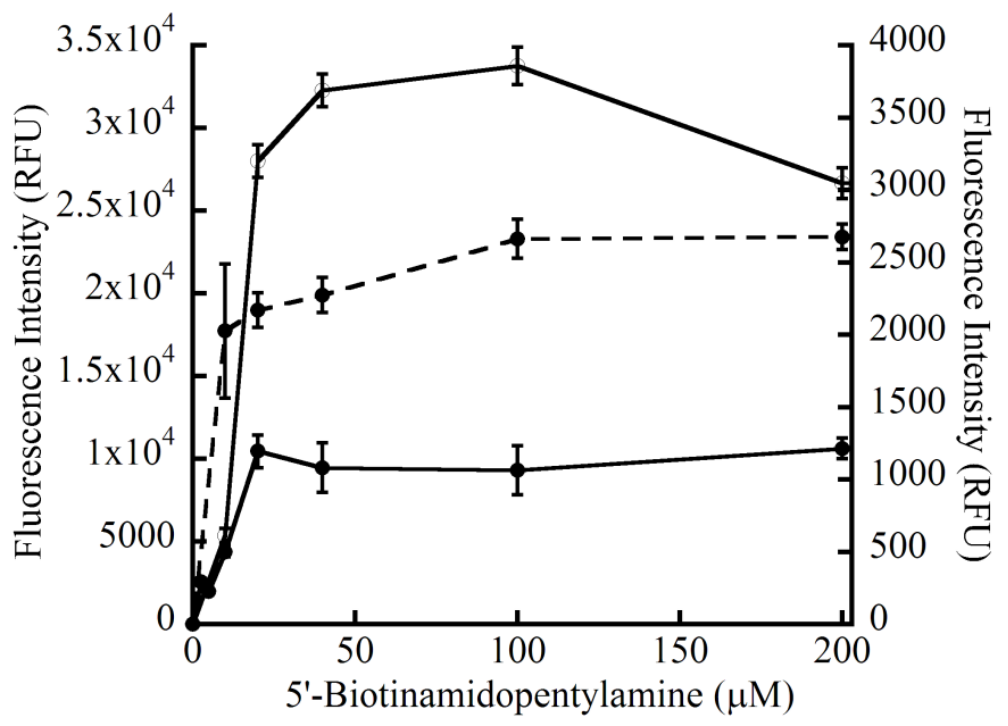

Fig. (5). Optimization of BP concentration for the measurement of TG activity using plasmonic fluorescent nanocomposites. Increasing and indicated concentrations of BP were 
used as substrate for crosslinking to DMC $(2.5 \mathrm{mg} / \mathrm{mL})$ at $37^{\circ} \mathrm{C}$ for 30 minutes. Open circles represent $1.5 \mu \mathrm{g} / \mathrm{mL}$ TG reactions probed using $25 \mu \mathrm{M}$ cyanine 1 whereas closed circles represent TG reactions probed using $10 \square \mathrm{M}$ cyanine $\mathbf{2}$ with the solid tracing being $0.75 \mu \mathrm{g} / \mathrm{mL}$ TG reactions and broken tracing being $1.5 \mu \mathrm{g} / \mathrm{mL}$ TG reactions. The left and right ordinates represent respectively, the fluorescence emission intensities from $\mathbf{1}$ and $\mathbf{2}$ plasmonic fluorescent nanocomposites. The concentration of 10nm AuNPs-SA was the same $\left(2.4 \times 10^{10} / \mathrm{mL}\right)$ in all three reactions.

\subsubsection{Optimization of plasmonic fluorescent nanocomposites}

We next determined the concentrations of cyanine $\mathbf{1}$ and $\mathbf{2}$ for eliciting maximal S/B values following TG catalysis under optimized catalytic conditions (Fig. 6). In these experiments we also combined the determination of intermediate precision (variability in an assay carried out on different days in the same lab and/or by the same investigator over several different days. ${ }^{[15]}$ Based on the results we estimated $25 \mu \mathrm{M}$ and $10 \mu \mathrm{M}$ concentrations of cyanine 1 and 2 to be optimal for the formation of plasmonic fluorescent nanocomposites. Similar results with relative standard deviations (RSD) of less than $20 \%$ were observed especially at the optimal concentrations for the two cyanine dyes indicating good intermediate precision (Fig. 6). The $25 \mu \mathrm{M}$ and $10 \mu \mathrm{M}$ of cyanine $\mathbf{1}$ and $\mathbf{2}$ were also the concentrations at which these two dyes approached the saturation of fluorescence (Fig. 2) as also reported previously. ${ }^{[5]}$ For example, a 5-fold increase in the concentration of $2(10 \mu \mathrm{M}$ to $50 \mu \mathrm{M})$ resulted in less than $30 \%$ increase in emission intensity from 2 nanocomposites (Fig. 2B, panel III). Likewise, doubling 1 concentration $(25 \mu \mathrm{M}$ to $50 \mu \mathrm{M})$ resulted in negligible increase in fluorescence emission from 1 nanocomposites (Fig. 2B, panel II). 


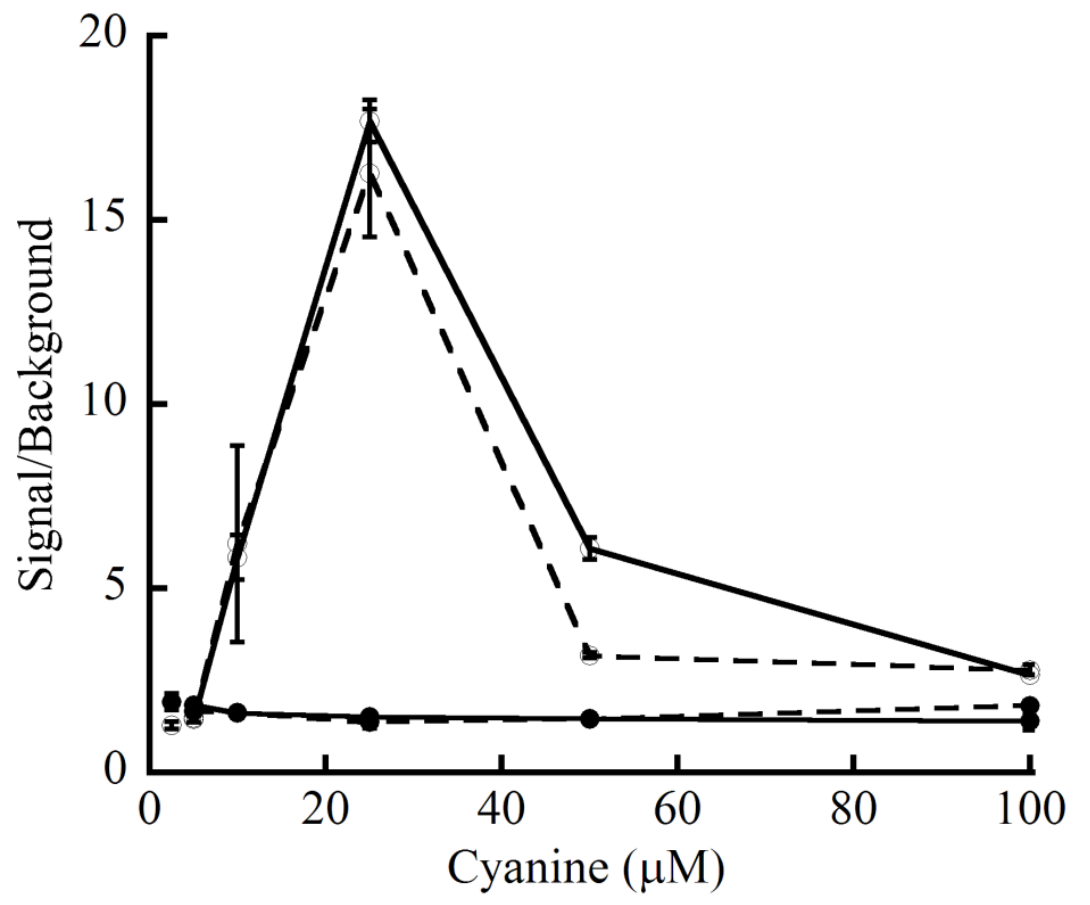

Fig. (6). Optimization of cyanine concentration for the signaling of TG activity using plasmonic fluorescent nanocomposites as well as intermediate precision. Increasing and indicated concentrations of cyanine $\mathbf{1}$ or $\mathbf{2}$ were used to facilitate the formation of plasmonic fluorescent nanocomposites upon 10nm AuNPs-SA $\left(2.4 \times 10^{11} / \mathrm{mL}\right)$ following enzymatic catalysis. TG $(7.4 \mu \mathrm{g} / \mathrm{mL})$ was used to crosslink $0.5 \mathrm{mM}$ solution of BP to DMC $(2.5 \mathrm{mg} / \mathrm{mL})$ at $37^{\circ} \mathrm{C}$ for 60 minutes. The open circles represent reactions probed using cyanine $\mathbf{1}$ and closed circles using cyanine 2 . The solid and broken tracings were from experiments conducted 42 days apart.

We then turned our attention toward the optimization of 10nm AuNPs-SA for TG catalysis. As seen from the data of Fig. 7, signal strength was optimal over a broad range of 10nm AuNPs-SA concentrations, spanning over two orders of magnitude with both cyanine $\mathbf{1}$ and 2. These results are reminiscent of our earlier data with these cyanine dyes self-assembling upon 10nm AuNPs-SA where cyanine $\mathbf{1}$ formed optimal plasmonic fluorescent nanocomposites over 3 orders of 10nm AuNPs-SA concentrations ranging from $1.9 \times 10^{9}$ to $1.6 \times 10^{11}$ particles $/ \mathrm{mL} \cdot{ }^{[5]}$ However, with cyanine 2 , we found that maximal fluorescence was at $\sim 10^{9}$ particles $/ \mathrm{mL}$ of $10 \mathrm{~nm}$ AuNPs-SA ${ }^{[5]}$, whereas in the present study we saw the signal saturating from $10^{9}$ up to $10^{11}$ particles $/ \mathrm{mL}$ (Fig. 7). It must be emphasized that the $10 \mathrm{~nm}$ AuNPs-SA concentrations of Fig. 2 are actual NPs/mL in these reaction wells. On the contrary, the NPs $/ \mathrm{mL}$ of Fig. 7 represents the concentrations of 10nm AuNPs added to the 
wells. It is probable that the concentrations shown in Fig. 7 are not equal to the amount of NPs that bound to the biotin in the TG reaction wells. In fact, it is likely to be lower. Such considerations explain the similarities and differences between the data of Figs. 2, 7, and earlier results. ${ }^{[5]}$ The decline in fluorescence intensity at flanking concentrations of $10 \mathrm{~nm}$ AuNPs-SA (Fig. 7) was also noted in earlier work ${ }^{[5]}$ confirming intermediate precision. We decided that 0.2 to $2.0 \times 10^{11}$ AuNPs-SA/mL concentrations were satisfactory for measuring TG activity.

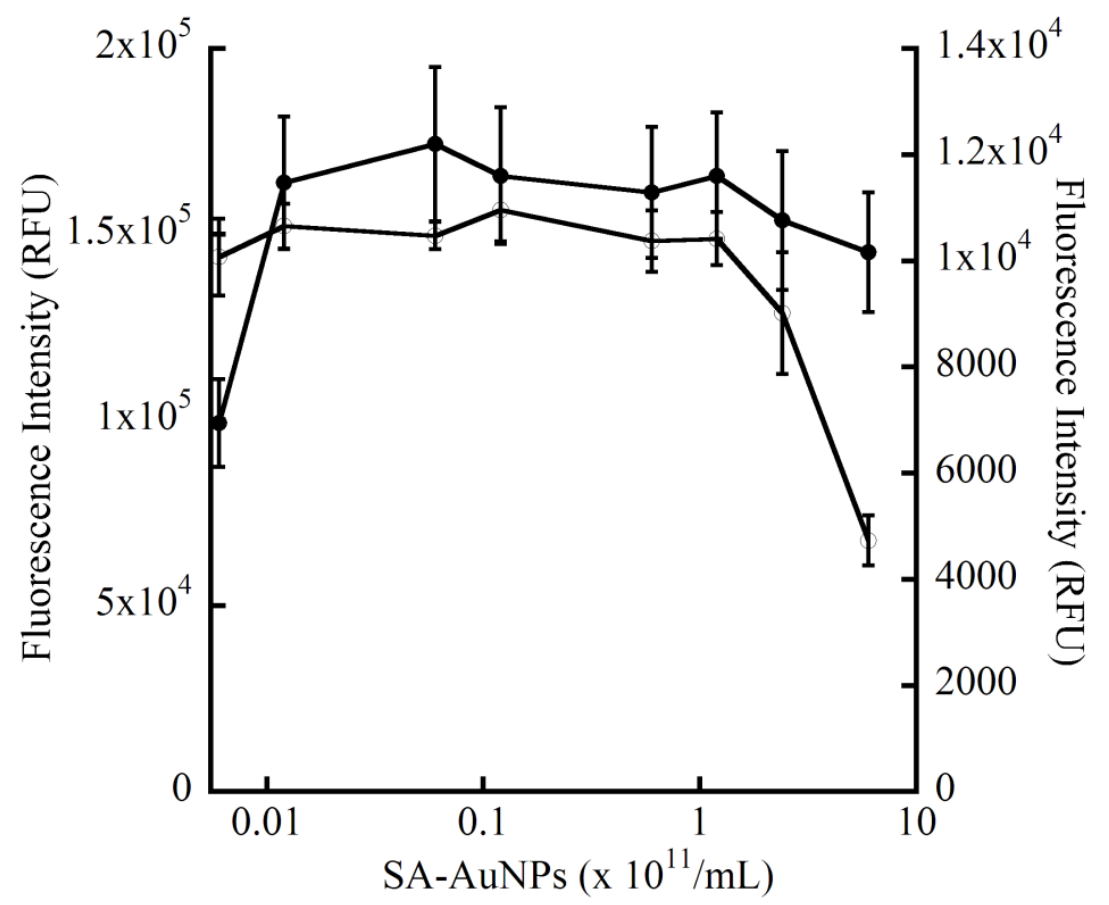

Fig. (7). Optimization of 10nm AuNPs-SA concentration for measurement of TG activity using plasmonic fluorescent nanocomposites. Increasing and indicated concentrations of $10 \mathrm{~nm}$ AuNPs-SA were used to facilitate the supramolecular self-assembly of $25 \mu \mathrm{M}$ of $\mathbf{1}$ (open circles) and $10 \mu \mathrm{M}$ of 2 (closed circles) plasmonic fluorescent nanocomposites. TG $(5.9 \mu \mathrm{g} / \mathrm{mL})$ was used to crosslink a $0.5 \mathrm{mM}$ solution of BP to DMC $(2.4 \mathrm{mg} / \mathrm{mL})$ at $37^{\circ} \mathrm{C}$ for 60 minutes.

\subsubsection{Reaction kinetics}

A key requirement of HTS assays is reaction kinetics. In our format, both TG kinetics and the kinetics of supramolecular plasmonic fluorescent nanocomposites formation are both critical for practical applications. As reported previously ${ }^{[5]}$ and observed during the current studies, the self-assembly of cyanines $\mathbf{1}$ and $\mathbf{2}$ upon 10nm AuNPs-SA scaffold was nearly 
instantaneous (signaling was within 1 to 2.5 minutes post-addition of the dye). This is an advantage in HTS where the speed of enzyme catalysis and the speed of the detection platform both impact the screening of hundreds of thousands of lead compounds during drug discovery. ${ }^{[15]}$ The S/B values of 2 plasmonic fluorescent nanocomposites degrade over time if emission measurements were not made immediately. This was due to the non-specific increase in background fluorescence of the 2 monomer. ${ }^{[5]}$ Due to these considerations, we routinely measured the fluorescence emission from both $\mathbf{1}$ and $\mathbf{2}$ nanocomposites 'immediately' after adding the dyes, thereby enabling "mix-and-measure" detection, a clear advantage in HTS assays. ${ }^{[15]}$

We then determined the TG enzyme kinetics in order to find out if the speed of our assay format was compatible with HTS conditions of drug discovery. The results are shown in Fig. 8. It is important to note that the current studies were carried out using 384-well plates for HTS compatibility, nevertheless involved manual pipetting. Consequently, the reaction kinetics was conducted at ambient temperature $\left(\sim 25^{\circ} \mathrm{C}\right)$ in order to minimize temperature fluctuations between the variously timed pipetting steps. Furthermore, to ensure complete inactivation of TG, following removal of the reaction mixture, the empty wells were filled with $\sim 120 \mu \mathrm{L}$ of $25 \mathrm{mM}$ EDTA (a potent inhibitor of $\mathrm{TG}^{[6,7]}$ ) while companion reactions of longer periods were proceeding. Given the difficulties of manual pipetting in 384-well plate, 2.5 minutes was the minimum time point at which TG activity could be reliably detected with linear $\left(r^{2}, 0.84\right.$ to 0.99$)$ kinetics up to 10 minutes at all concentrations of TG tested and probed using cyanine $\mathbf{1}$ or $\mathbf{2}$ (Fig. 8). As usual, the fluorescence intensity from $\mathbf{2}$ nanocomposites was approximately 10-fold lower than $\mathbf{1}$ nanocomposites for comparable concentrations of TG enzyme protein.

The linear reaction kinetics was similar to the previously reported radioisotope assay linearity between 2 to 10 minutes $^{[28]}$, except that our assay eschewed hazardous radioactive chemicals. Clearly, 2.5 minutes reaction is in the timeframe of a HTS environment ${ }^{[31,32]}$, especially when considered within the context of a previously reported 15 minutes reaction using a minimum of $1.5 \mu \mathrm{g}$ TG per reaction per well $(\sim 25 \mu \mathrm{g} / \mathrm{mL}$ TG), which was characterized as a "rapid transglutaminase assay". ${ }^{[33]}$ The kinetics also compared favorably with the reported reaction 
times of 5 to 20 minutes used with other types of fluorescent or radioactive assays. ${ }^{[13,27,29,34]}$ Our kinetic results are superior to other previously published TG assays based on scintillation proximity or ammonia formation, where progress curves were charted over the course of several hours to more than 24 hours. ${ }^{[35,36]}$ The current HTS TG assay is also attractive due to the near-instantaneous signaling from plasmonic fluorescent nanocomposites when combined with the real-world advantages of robotics and automated liquid handling facilities that are common in pharmaceutical industry. ${ }^{[15]}$

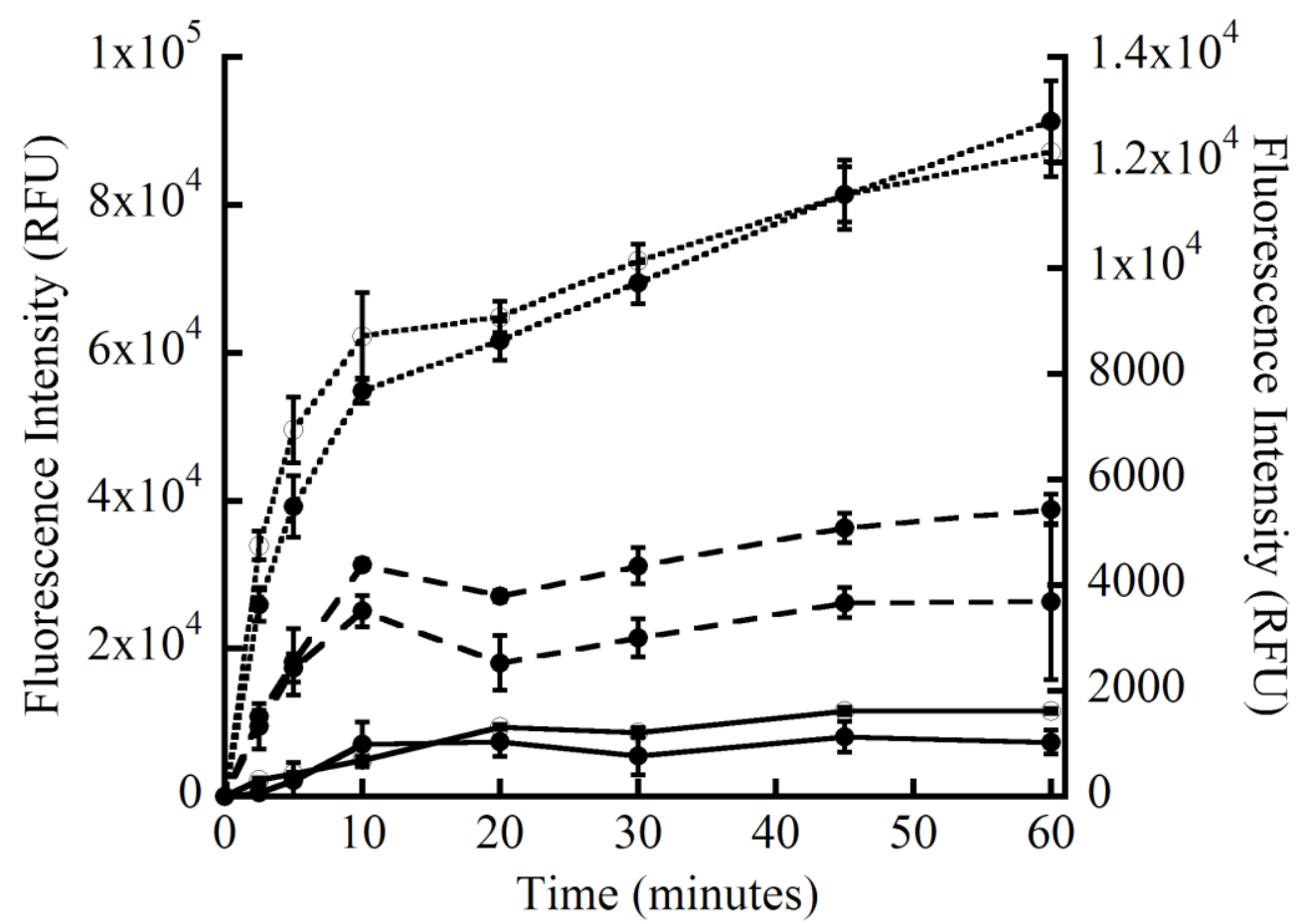

Fig. (8). Kinetics of TG activity using plasmonic fluorescent nanocomposites. TG catalysis was carried out over the indicated time periods and then probed by the formation of plasmonic fluorescent nanocomposites of cyanine $\mathbf{1}$ or $\mathbf{2}$. The solid, broken and dotted tracings are from crosslinking of $0.5 \mathrm{mM}$ BP to DMC $(2.5 \mathrm{mg} / \mathrm{mL})$ by $1.25,2.5$ and 5.0 $\square \mathrm{g} / \mathrm{mL}$ TG, respectively. Open and closed circles represent TG catalysis probed using $25 \square \mathrm{M}$ and $10 \square \mathrm{M}$ cyanine $\mathbf{1}$ and $\mathbf{2}$, respectively. The concentration of 10nm AuNPs-SA in all reaction wells was $2.4 \times 10^{10} / \mathrm{mL}$.

\subsubsection{Assay simplification}

Another important parameter that should be considered while transitioning assays to HTS is design simplicity. ${ }^{[15]}$ We therefore determined whether one type of plasmonic fluorescent nanocomposites, after taking fluorescence measurements, could be displaced and then the 
same reaction wells be interrogated using the second type of plasmonic fluorescent nanocomposites, by the sequential addition of cyanines $\mathbf{1}$ and $\mathbf{2}$ or vice versa. The results of these experiments are depicted in Fig. 9 and yielded some very interesting data. It appeared that sequential interrogation of the reaction wells was unidirectional, i.e., addition of $\mathbf{1}$ followed by the addition of $\mathbf{2}$, and not the other way around. Thus, the overall signal strength and the TG dose-response tracings were nearly super-imposable when the reaction wells were probed using $\mathbf{2}$ "alone" or by probing with 1 first, taking fluorescence measurements of 1 nanocomposites, displacing the 1-nanocomposites by washing the wells, and then reprobing using 2 (Fig. 9). On the other hand, probing the reaction wells using 2 first and then with 1, led to fluorescence diminishing (quenching). Clearly, probing the reaction wells first with 2 interfered with the subsequent formation of $\mathbf{1}$ nanocomposites. This may simply be due to the difficulty in completely removing the $\mathbf{2}$ nanocomposites by washing the wells. As reported previously ${ }^{[5]}$, the formation of $\mathbf{1}$ and $\mathbf{2}$ plasmonic fluorescent nanocomposites was also accompanied by the characteristic color transitions (1 nanocomposites, orange-tomagenta; 2 nanocomposites, purple-to-teal). After probing first with 1, the washed white wells were still stained pink. Likewise, rigorous washing of wells probed with 2 first, were stained purple-teal. This indicated insufficient removal of both $\mathbf{1}$ and $\mathbf{2}$ nanocomposites by washing. Nevertheless, the prior formation of $\mathbf{2}$ nanocomposites somehow appeared to interfere with the subsequent formation of $\mathbf{1}$ nanocomposites. The data do point to at least one technique for assay simplification without compromising data quality, and that is to probe the reaction wells with $\mathbf{1}$ first, followed by the formation of $\mathbf{2}$ plasmonic fluorescent nanocomposites (Fig. 9). Of course, the reactions could also be probed independently using 1 and 2 nanocomposites which would however require independent sets of reactions, thus potentially doubling the experimental load. Our heterogeneous HTS format is of a similar design simplicity with regard to the number of procedural steps when compared to previously published HTS assays. ${ }^{[13,30,33,34]}$

From the data of Fig. 9, we also extracted the sensitivity of the TG HTS assay that was based on plasmonic fluorescent nanocomposites signaling. The linear dynamic range (LDR) was similar with both 1 and 2 nanocomposites ( 0.1 to $5 \mu \mathrm{g} / \mathrm{mL} ; r^{2}=0.98$ to 0.99; Fig. 9, inset). We estimated the limits of detection and quantitation (LOD, LOQ; ${ }^{[15]}$ ) of TG to be 0.1 and 
$0.75 \mu \mathrm{g} / \mathrm{mL}$ using 1 nanocomposites and 2 and $10 \mu \mathrm{g} / \mathrm{mL}$ with 2 nanocomposites, once again confirming the superior performance of cyanine 1 (5ng TG) relative to 2 (100ng TG). Using a molecular mass of $80 \mathrm{kDa}$ for purified guinea pig liver $\mathrm{TG}^{[7]}$, we estimated the LOD to be $64 \mathrm{fmol} \mathrm{TG}$ with 1 nanocomposites signaling. These data compare favorably with previously reported TG LOD values of $0.05 \mu \mathrm{g} / \mathrm{mL}^{[13]}, 0.25 \mu \mathrm{g} / \mathrm{mL}^{[30]}, 100 \mathrm{ng}^{[34]}, 4.2 \mathrm{ng}^{[29]}$, and $3 \mathrm{ng}{ }^{[33]}$ The TG dose-response range shown in Fig. 9 was also comparable to previously published guinea pig liver TG assays reporting 0.2 to $1.6 \mu \mathrm{g} / \mathrm{mL}$ linearity with a ${ }^{14} \mathrm{C}$-putrescine incorporation assay ${ }^{[34]}, 2$ to $16 \mu \mathrm{g} / \mathrm{mL}$ linearity using a fluorescent dot-blot assay ${ }^{[34]}$, and the 0.1 to $0.8 \mu \mathrm{g} / \mathrm{mL}$ linearity of an absorption-based microplate assay. ${ }^{[13]}$

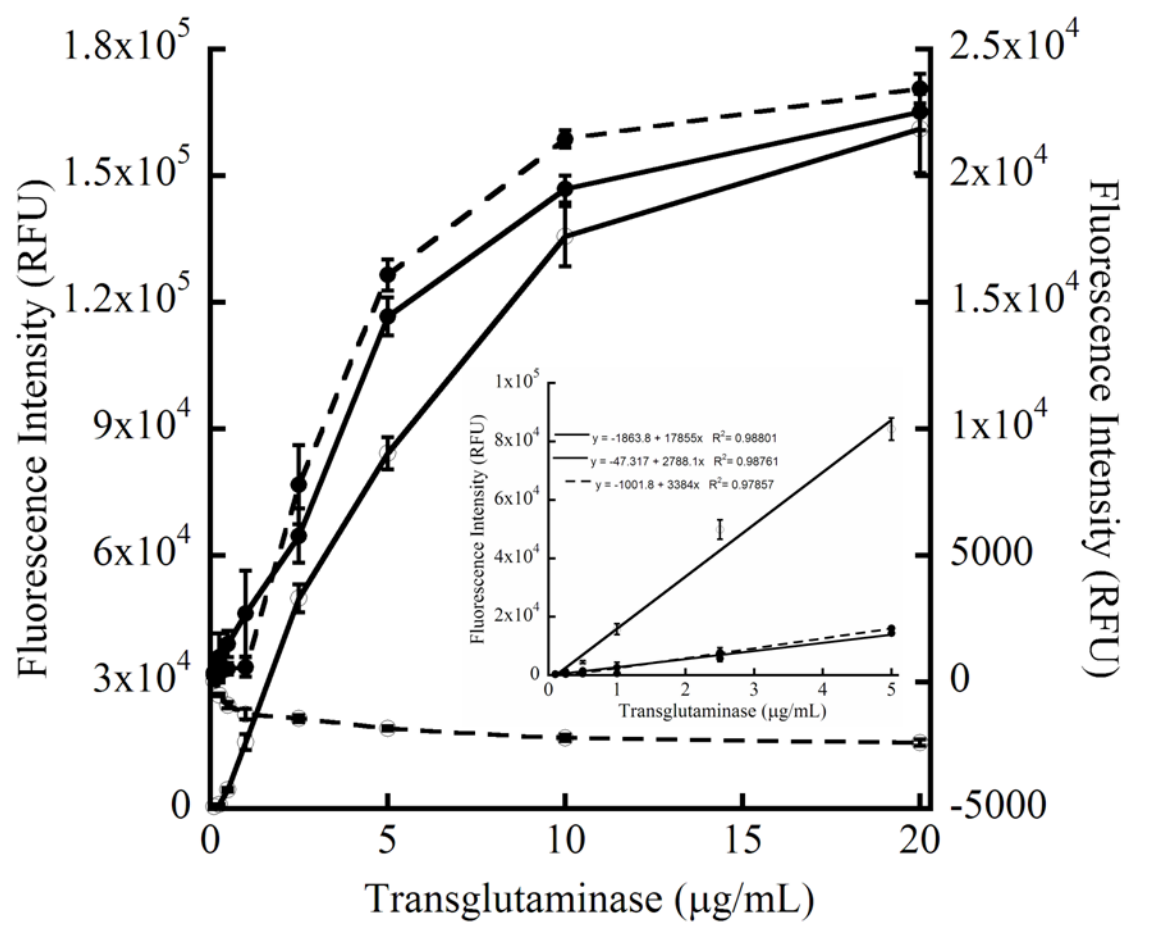

Fig. (9). Addition sequence of 1 and 2 in the formation of plasmonic fluorescent nanocomposites and linear dynamic range (LDR). TG catalysis $(2.5 \mathrm{mg} / \mathrm{mL}$ DMC; $0.5 \mathrm{mM}$ $\mathrm{BP} ; 37^{\circ} \mathrm{C}, 30$ minutes) were probed by adding $1(25 \mu \mathrm{M}$; open circles) or $2(10 \mu \mathrm{M}$; closed circles) first, carrying out fluorescence measurements, washing the wells free of that dye and then probing the reaction wells using the other cyanine. Solid tracings are signals from $\mathbf{1}$ or $\mathbf{2}$ "alone" whereas broken tracings represent sequential additions. The left ordinate is the fluorescence emission from 1 nanocomposites whereas the right ordinate represents the emissions from $\mathbf{2}$ nanocomposites, $\mathbf{2}$ nanocomposites followed by the formation of $\mathbf{1}$ nanocomposites, and $\mathbf{1}$ nanocomposites followed by the formation of $\mathbf{2}$ nanocomposites. The inset shows the LDR for TG catalysis. The 10nm AuNPs-SA concentration was $2.4 \mathrm{x}$ $10^{10} / \mathrm{mL}$. 


\subsubsection{Absorption assay}

We finally examined the red-shifted absorption changes consequent to the aggregation of cyanines 1 and 2 upon 10nm AuNPs-SA scaffold. ${ }^{[5,12]}$ Employing multiple, distinct technologies for signaling will improve the overall assay specificity by minimizing false positives and/or false negatives, since the fundamental principles of interrogation are unique to each technique and independent of one another ${ }^{[15]}$ Thus, orthogonal signaling is preferable during HTS assay development. Cyanine J-aggregates are characterized by both absorption and fluorescence red shifts. ${ }^{[12]}$ The results showed that absorption is also a useful, albeit less sensitive tool for examining TG catalysis with $\mathbf{1}$ and $\mathbf{2}$ plasmonic fluorescent nanocomposites (Fig. 10). This is to be expected since it is well established that fluorescence is the more sensitive technique and is indeed considered to be the "gold standard" for HTS assays. ${ }^{[15]}$ It was estimated that the absorption assays with $\mathbf{1}$ and $\mathbf{2}$ nanocomposites were 100- and 5-fold less sensitive relative to their respective fluorescent counterparts. The LOD in absorption assays were estimated to be $5 \mu \mathrm{g} / \mathrm{mL}$ (500ng or 6.4 pmol TG) with both 1 and 2 nanocomposites (Fig. 10). We had seen 2-10-fold or stronger absorption signals from 2 nanocomposites relative to $\mathbf{1}^{[5 \text {; see also Fig. } 2 \mathrm{~A}]}$ and this trend seemed to reappear with the TGcatalyzed data of Fig. 10. As commented above, using clear plates will enable absorption and fluorescence signaling within a single plate assay format.

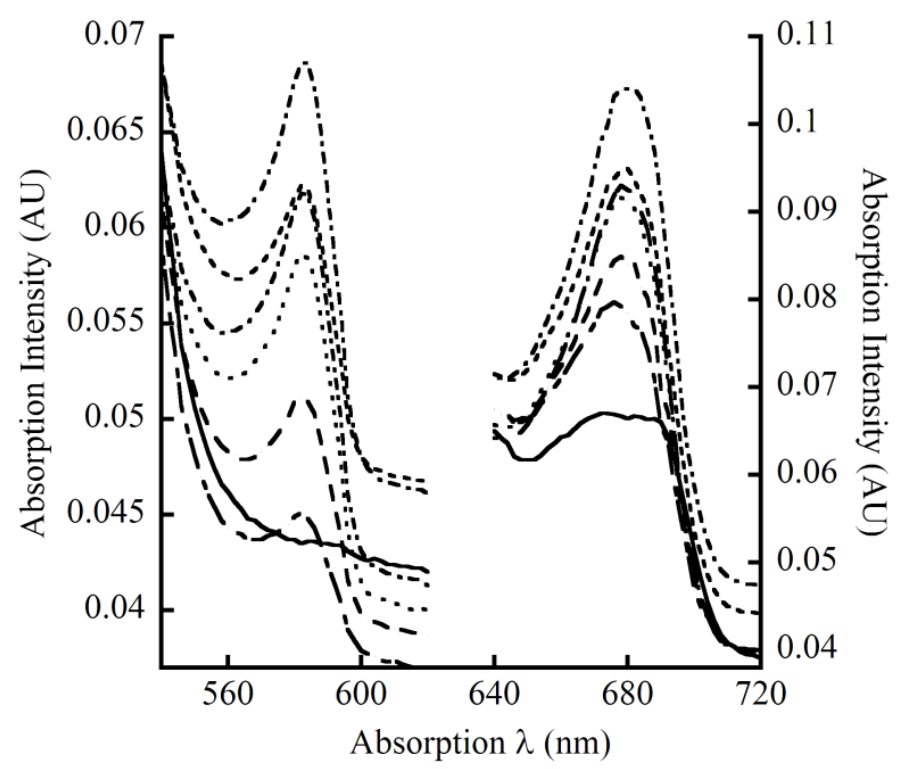

Fig. (10). Monitoring TG catalysis by red-shifted absorption changes from the plasmonic nanocomposites of 1 (left panel) or 2 (right panel). The solid black tracings in both panels 
represent "control" absorption of $\mathbf{1}$ and $\mathbf{2}$ in the absence of TG and the various broken tracings of increasing absorption intensities represent catalysis using 5, 10, 25, 50, 75 and $100 \mu \mathrm{g} / \mathrm{mL}$ TG crosslinking a $0.5 \mathrm{mM}$ solution of BP to DMC $(2.5 \mathrm{mg} / \mathrm{mL})$ immobilized in 384-well clear plate. TG reactions were carried out at $37^{\circ} \mathrm{C}$ for 30 minutes and absorption changes were probed at ambient temperature $\left(\sim 25^{\circ} \mathrm{C}\right)$. The $10 \mathrm{~nm}$ AuNPs-SA concentration was $2.4 \times 10^{10} / \mathrm{mL}$.

\subsection{Conclusions}

We have demonstrated for the first time, an application of plasmonic fluorescent nanocomposites for the HTS of TG activity. The assay compares favorably in terms of speed, simplicity, and sensitivity with previously published screens for TG activity that were based on other types of signaling techniques. The red-shifted absorption and fluorescence wavelengths, especially the near-infrared (NIR) emissions of 2 nanocomposites, will be beneficial in minimizing the blue-green autofluorescence and scattering intrinsic to biological samples and thereby improve assay specificity. ${ }^{[15,23,24]}$ Cyanine J-aggregates such as those of 1 and 2 nanocomposites can also be detected through electrochemical techniques ${ }^{[12,37-39]}$, adding yet another orthogonal technique to the suite of interrogation tools, for further improvements to the twin key parameters of HTS, i.e., sensitivity and specificity. ${ }^{[15]}$ Other techniques might be to directly measure the characteristic LSPR absorption of the AuNPs or detect AuNPs using electrochemistry or from Surface Enhanced Raman spectroscopy (SERS) signatures ${ }^{[1,40]}$ and thereby eliminating cyanine self-assembly altogether. The assay might eventually be adapted to a microarray format based on immobilized DMC amine substrates. ${ }^{[26,41]}$ We believe that this report shows the industry-relevant applications of the nascent field of plasmonic fluorescent nanocomposites. Such practical applications will further drive the use of plasmonic fluorescent nanocomposites for novel chem-bio-sensors development. 


\subsection{References}

[1] Daniel, M.C.; Astruc, D. Gold nanoparticles: assembly, supramolecular chemistry, quantum-size-related properties, and applications toward biology, catalysis, and nanotechnology. Chem. Rev., 2004, 104, 293-346.

[2] Jin, Y.; Gao, X. Plasmonic fluorescent quantum dots. Nat. Nanotechnol., 2009, 4, 571576.

[3] Aslan, K.; Wu, M.; Lakowicz, J.R.; Geddes, C.D. Fluorescent core-shell Ag@ $\mathrm{SiO}_{2}$ nanocomposites for metal-enhanced fluorescence and single particle sensing platforms. $J$. Am. Chem. Soc., 2007, 129, 1524-1525.

[4] Stranik, O.; Nooney, R.; McDonagh, C.; MacCraith, B.D. Optimization of nanoparticle size for plasmonic enhancement of fluorescence. Plasmonics, 2007, 2, 15-22.

[5] Achyuthan, K.E.; Achyuthan, A.M.; Brozik, S.M.; Dirk, S.M.; Lujan, T.R.; Romero, J.M.; Whitten, D.G.; Harper, J.C. High-throughput screening of plasmonic fluorescent nanocomposites of cyanines self-assembled upon gold nanoparticle scaffolds. ACS Appl. Mater. Interfaces, 2011, (submitted).

[6] Serafini-Fracassini, D.; Del Duca, S. Transglutaminases: widespread cross-linking enzymes in plants. Ann. Bot., 2008, 102, 145-152.

[7] Park, D.; Choi, S.S.; Ha, K.S. Transglutaminase 2: a multi-functional protein in multiple subcellular compartments. Amino Acids, 2010, 39, 619-631.

[8] Wodzinska, J.M. Transglutaminases as targets for pharmacological inhibition. Mini Rev. Med. Chem., 2005, 5, 279-292.

[9] Case, A.; Ni, J.; Yeh, L.A.; Stein, R.L. Development of a mechanism-based assay for tissue transglutaminase - results of a high-throughput screen and discovery of inhibitors. Anal. Biochem., 2005, 338, 237-244.

[10] Lai, T.S.; Liu, Y.; Tucker, T.; Daniel, K.R.; Sane, D.C.; Toone, E.; Burke, J.R.; Strittmatter, W.J.; Greenberg, C.S. Identification of chemical inhibitors to human tissue transglutaminase by screening existing drug libraries. Chem. Biol., 2008, 15, 969-978.

[11] Weber, P.C.; Ohlendorf, D.H.; Wendoloski, J.J.; Salemme, F.R. Structural origins of high-affinity biotin binding to streptavidin. Science, 1989, 243, 85-88.

[12] Mishra, A.; Behera, R.K.; Behera, P.K.; Mishra, B.K.; Behera, G.B. Cyanines during the 1990s: a review. Chem. Rev., 2000, 100, 1973-2011. 
[13] Slaughter, T.F.; Achyuthan, K.E.; Lai, T.S.; Greenberg, C.S. A microtiter plate transglutaminase assay utilizing 5-(biotinamido)pentylamine as substrate. Anal. Biochem., 1992, 205, 166-171.

[14] Fox, P.F.; Whitaker, J.R.; O’Leary, P.A. Isolation and characterization of sheep pepsin. Biochem. J., 1977, 161, 389-398.

[15] Achyuthan, K.E.; Whitten, D.G. Design considerations for high throughput screening and in vitro diagnostic assays. Comb. Chem. HTS., 2007, 10, 399-412.

[16] Pockrand, I.; Brillante, A.; Mobius, D. Nonradiative decay of excited molecules near a metal surface. Chem. Phys. Lett. 1980, 69, 499-504.

[17] Yoshida, A.; Kometani, N. Synthesis and spectroscopic properties of silver:dye composite nanoparticles with a double-shell structure Phys. Status Solidi C 2010, 7, 26522655.

[18] Tam, F.; Goodrich, G.P.; Johnson, B.R.; Halas, N.J. Plasmonic enhancement of molecular fluorescence. Nano Lett. 2007, 7, 496-501.

[19] Yoshida, A.; Uchida, N.; Kometani, N. Tuning of the spectroscopic properties of composite nanoparticles by the insertion of a spacer layer: effect of exciton-plasmon coupling. Langmuir 2009, 25, 6683-6689.

[20] Bardhan, R.; Grady, N.K.; Cole, J.R.; Joshi, A.; Halas, N.J. Fluorescence enhancement by Au nanostuctures: nanoshells and nanorods. ACS Nano 2009, 3, 744-752.

[21] Yoshida, A.; Uchida, N.; Kometani, N. Synthesis and spectroscopic studies of composite gold nanorods with a double-shell structure composed of spacer and cyanine dye J-aggregate layers. Langmuir 2009, 25, 11802-11807.

[22] Vasil'ev, D.N.; Koltsova, E.S.; Chubich, D.A. Effect of the plasmon-exciton interaction on optical properties of core-shell nanoparticles. Bull. Lebedev Phys. Inst. 2010, 37, 87-88.

[23] Li, X.; Shi, W.; Chen, S.; Jia, J.; Ma, H.; Wolfbeis, O.S. A near-infrared fluorescent probe for monitoring tyrosinase activity. Chem. Commun. 2010, 46, 2560-2562.

[24] Stranik, O.; McEvoy, H.M.; McDonagh, C.; MacGraith, B.D. Plasmonic enhancement of fluorescence for sensor applications. Sensors Actuators B 2005, 107, 148-153.

[25] Achyuthan, K.E.; Adams, P.D.; Datta, S.; Simmons, B.A.; Singh, A.K. Hitherto unrecognized fluorescence properties of coniferyl alcohol. Molecules, 2010, 15, 1645-1667. 
[26] Kamiya, N.; Doi, S.; Tominaga, J.; Ichinose, H.; Goto, M. Transglutaminase-mediated protein immobilization to casein nanolayers created on a plastic surface. Biomacromolecules, 2005, 6, 35-38.

[27] Case, A.; Stein, R.L. Kinetic analysis of the action of tissue transglutaminase on peptide and protein substrates. Biochem., 2003, 42, 9466-9481.

[28] Madi, A.; Karpati, L.; Kovacs, A.; Muszbek, L.; Fesus, L. High-throughput scintillation proximity assay for transglutaminase activity measurement. Anal. Biochem., 2005, 343, 256262.

[29] Jeitner, T.M.; Fuchsbauer, H.L.; Blass, J.P.; Cooper, A.J.L. A sensitive fluorometric assay for tissue transglutaminase. Anal. Biochem., 2001, 292, 198-206.

[30] Park, J.Y.; Jung, S.H.; Jung, J.W.; Kwon, M.H.; Yoo, J.O.; Kim, Y.M.; Ha, K.S. A novel array-based assay of in situ tissue transglutaminase activity in human umbilical vein endothelial cells. Anal. Biochem., 2009, 394, 217-222.

[31] Yazbeck, D.R.; Tao, J.; Martinez, C.A.; Kline, B.J.; Hu, S. Automated enzyme screening methods for the preparation of enantiopure pharmaceutical intermediates. Adv. Synth. Catal., 2003, 345, 524-532.

[32] Goueli, S.A.; Hsia, K.; Bulleit, B. A homogeneous, luminescent, high-throughput, versatile assay for a wide range of kinases. Handbook of Assay Development in Drug Discovery, Ed., Minor, L.K., 2006, Ch. 8, 97-112.

[33] Wu, Y.W.; Tsai, Y.H. A rapid transglutaminase assay for high-throughput screening applications. J. Biomol. Screen., 2006, 11, 836-843.

[34] McConoughey, S.J.; Niatsetskaya, Z.V.; Pasternack, R.; Hils, M.; Ratan, R.R.; Cooper, A.J.L. A non-radioactive dot-blot assay for transglutaminase activity. Anal. Biochem., 2009, 390, 91-93.

[35] Zhao, X.; Shaw, A.C.; Wang, J.; Chang, C.C.; Deng, J.; Su, J. A novel high-throughput screening method for microbial transglutaminses with high specificity toward Gln141 of human growth hormon. J. Biomol. Screen., 2010, 15, 206-212.

[36] de Jong, G.A.H.; Wijngaard, G.; Boumans, H.; Koppelman, S.J.; Hessing, M. Purification and substrate specificity of transglutaminases from blood and Streptoverticillium mobaraense. J. Agric. Food Chem., 2001, 49, 3389-3393. 
[37] Lenhard, J.R.; Hein, B.R. Effect of J-aggregation on the redox levels of a cyanine dye. $J$. Phys. Chem. 1996, 100, 17287-17296.

[38] Zhang, L; Li, X.; Mu, J. Self-assembly of porphyrin-based supramolecules and their characteristics on gold nanoparticles. Colloids Surf. A 2007, 302, 219-224.

[39] Lyon, J.L.; Eisele, D.M.; Kirstein, S.; Rabe, J.P.; Vanden Bout, D.A.; Stevenson, K.J. Spectroelectrochemical investigation of double-walled tubular J-aggregates of amphiphilic cyanine dyes. J. Phys. Chem. C 2008, 112, 1260-1268.

[40] Eustis, S.; El-Sayed, M.A. Why gold nanoparticles are more precious than pretty gold: noble metal surface plasmon resonance and its enhancement of the radiative and nonradiative properties of nanocrystals of different shapes. Chem. Soc. Rev., 2006, 35, 209-217.

[41] Kwon, M.H.; Jung, J.W.; Jung, S.H.; Park, J.Y.; Kim, Y.M.; Ha, K.S. Quantitative and rapid analysis of transglutaminase activity using protein arrays in mammalian cells. Mol. Cells, 2009, 27, 337-343. 


\section{DISTRIBUTION LiST}

$1 \quad$ MS 0899

RIM-Reports Management, 9532

$1 \quad$ MS 0359

Donna Chavez, LDRD office, 1911 


\section{(17) Sandia National Laboratories}

